Chapman University

Chapman University Digital Commons

Accounting Faculty Articles and Research

Accounting

6-16-2018

\title{
Corporate Governance Roles of Information Quality and Corporate Takeovers
}

Jing Li

University of Hong Kong

Lin Nan

Purdue University

Ran Zhao

Chapman University, rzhao@chapman.edu

Follow this and additional works at: https://digitalcommons.chapman.edu/accounting_articles

Part of the Business Administration, Management, and Operations Commons, Business Intelligence Commons, Business Law, Public Responsibility, and Ethics Commons, Organizational Behavior and Theory Commons, and the Other Business Commons

\section{Recommended Citation}

Li, J., Nan, L. \& Zhao, R. (2018). Corporate governance roles of information quality and corporate takeovers. Review of Accounting Studies, 23(3): 1207-1240. doi: 10.1007/s11142-018-9449-z

This Article is brought to you for free and open access by the Accounting at Chapman University Digital Commons. It has been accepted for inclusion in Accounting Faculty Articles and Research by an authorized administrator of Chapman University Digital Commons. For more information, please contactlaughtin@chapman.edu. 


\section{Corporate Governance Roles of Information Quality and Corporate Takeovers}

\section{Comments}

This is a pre-copy-editing, author-produced PDF of an article accepted for publication in Review of Accounting Studies, volume 23, issue 3, in 2018 following peer review. The final publication is available at Springer via DOI:10.1007/s11142-018-9449-z.

\section{Copyright}

Springer 


\title{
Corporate Governance Roles of Information Quality and Corporate Takeovers *
}

\author{
Jing Lił Lin Nan $\stackrel{\ddagger}{\ddagger}$ Ran Zhao ${ }^{\S}$
}

February 20, 2018

\begin{abstract}
We examine the corporate governance roles of information quality and the takeover market with asymmetric information regarding the value of the target firm. Increasing information quality improves the takeover efficiency, however, a highly efficient takeover market also discourages the manager from exerting effort. We find that perfect information quality is not optimal for either the current shareholders' expected payoff maximization or the expected firm value maximization. Furthermore, the current shareholders prefer a lower level of information quality than the level that maximizes the expected firm value, because of a misalignment between the current shareholders' welfare and the total firm value. We also analyze the impact of antitakeover laws, and we find that the passage of antitakeover laws may induce the current shareholders to choose a higher level of information quality and thus increase the expected firm value.
\end{abstract}

${ }^{*}$ We would like to thank Tim Baldenius, Anne Beyer, Judson Caskey, Carlos Corona, Jon Glover, Ilan Guttman, Mirko Heinle, John Hughes, Bjorn Jorgensen, Pierre Liang, John O’Brien, Ram Ramanan, Stefano Sacchetto, Jack Stecher, seminar participants at Carnegie Mellon University, New York University, participants at the 2012 Junior Accounting Theory Conference, and participants at the 2013 Financial Accounting and Reporting Section meeting for their helpful comments.

${ }^{\dagger}$ University of Hong Kong, acjli@hku.hk.

${ }^{\ddagger}$ Purdue University, lnan@purdue.edu.

${ }^{\S}$ Chapman University, rzhao@chapman.edu. 


\section{Introduction}

Financial accounting information provides direct input in the design of corporate governance mechanisms (Bushman and Smith, 2001; Armstrong, Guay and Weber, 2010). Most theoretical studies on the role of accounting information in corporate governance have concentrated on executive compensation and performance measures in agency-based models, ${ }^{1}$ while the role of accounting information with respect to other corporate governance mechanisms remains underexplored. In this paper, we provide a theoretical model to examine the governance roles of information quality and an important external governance mechanism - the corporate takeover market.

Recently, the role of financial reporting in facilitating takeover markets has gained attention from empirical researchers. For example, several empirical studies have examined whether the information quality of financial reporting influences the profitability and efficiency of acquisitions (Francis and Martin, 2010; Ramen, Shivakumar, and Tamayo, 2013; McNichols and Stubben, 2015). In general, these studies focus on the perspective of acquirers and find that higher quality accounting information reduces the information asymmetry between the target and the acquirer, and allows the acquirer to better evaluate the target and bid more efficiently. However, it is unclear whether target firms have an incentive to increase information quality to improve takeover efficiency for the acquirers. Moreover, despite the growing interest of empirical studies in this area, no theoretical models have examined the role of financial information in takeovers. Our study is among the first to provide an analytical analysis to better understand the interaction between the information quality of financial reports and the takeover market as corporate governance mechanisms.

In our model, the takeover market serves two important functions. First, the takeover creates synergy values that improve shareholders' welfare. Prior studies have shown that such synergies may come from improved operating efficiency, reduced capital investment, tax benefits or market power (Bradley, Desai, and Kim, 1988; Hayn, 1989; Kim and Singal, 1993; Devos, Kadapakkam, Krishnamurthy, 2009). ${ }^{2}$ Second, the incumbent manager loses his private benefit of control after a successful takeover, which is more likely to occur if the manager shirks. ${ }^{3}$ Hence, the takeover market also serves as an incentive device to motivate

\footnotetext{
${ }^{1}$ Bushman and Smith (2001) and Armstrong et al. (2010) both provide detailed reviews of this literature.

${ }^{2}$ For example, in the recent acquisition of Tim Hortons by Burger King backed by Berkshire Hathaway, analysts and investors expect that the acquisition will create synergies through market expansion opportunities and tax savings.

${ }^{3}$ Previous studies such as Martin and McConnell (1991), and Kini, Kracaw, and Mian (2004) document a significant CEO turnover during takeovers, and also find a negative relation between the pre-takeover performance and post-takeover CEO turnovers. Even if a CEO remains in place, he/she may lose the power
} 
the incumbent manager. However, an efficient takeover market may have a negative effect on the manager's effort incentive if a high-value firm could also be taken over.

Information asymmetry exists in the takeover bidding: the acquirer observes a noisy accounting signal regarding the target firm value, while the target shareholders observe the true firm value. The acquirer chooses her optimal bidding strategy contingent on the observed signal, and the bidding strategy is affected by the informativeness of the signal. The current shareholders choose the information quality level to maximize their own payoff, including both the current firm value and potential premiums from the takeover. ${ }^{4}$

Increasing information quality has two primary effects. On the one hand, more precise accounting signals reduce the information asymmetry between the acquirer and the target shareholders. As a result, the acquirer, less concerned about the overbidding loss, is willing to bid more aggressively, increasing the likelihood of takeover success. On the other hand, the manager, knowing that his private benefit is more likely to be deprived by a more efficient takeover market, is less motivated to exert effort in the first place. The tradeoff of aforementioned two primary effects determines the optimal information quality level. We find that a perfectly informative information system is not optimal for either the the current shareholders' expected payoff or the expected firm value maximization, mainly because of the negative effect of higher information quality on the manager's effort.

We also find that the current shareholders' choice of information quality is different from the information quality level that maximizes the expected firm value, because the current shareholders' welfare and the expected firm value are not fully aligned. The expected firm value consists of two parts: the expected firm value without takeover and the expected synergy value from the takeover. For the current shareholders, their expected payoff is different from the expected firm value because they only obtain a portion of the synergy value from takeover; furthermore, they obtain an overbidding premium when the firm value is low but the acquirer offers a high price. We find that the current shareholders overall prefer a lower information quality level than that needed to maximize the firm value, mainly because the current shareholders do not enjoy the full synergy value from the takeover. Our results highlight the difference between current shareholders' welfare and the firm value

of making decisions or cannot enjoy the same private benefit as before after the acquirer takes control.

${ }^{4}$ The "information quality" in our paper can be interpreted as the informativeness of financial reporting or the quality of the information system. A system with higher information quality provides more accurate signals about firm values and facilitates valuations by investors. As suggested by Armstrong et al. (2010), the board of directors can affect the firm's information environment through (or compel the manager to commit to) several mechanisms, including a commitment to timely financial information, hiring a high-quality auditor and establishing an independent audit committee, inviting financial experts as outside directors, and maintaining or encouraging more active investors as monitors. 
that represents the welfare of all shareholders - current and future. This difference is often overlooked by regulators and academics.

In addition, we study the impact of antitakeover laws on firms' endogenous information quality as well as on the current shareholders' welfare and the firm value. Antitakeover laws have been controversial in regards to regulating the takeover market. Researchers and practitioners have debated for years whether antitakeover laws improve or reduce shareholders' wealth (Straska and Waller, 2014). One element missing from previous studies is the endogenous choice of information quality. Our study shows that current shareholders may increase the information quality to maximize their expected payoff in response to the passage of antitakeover laws. With a higher information quality, the expected firm value also increases after the passage of antitakeover laws. This result provides interesting implications that differ from conventional wisdom on the impact of antitakeover laws on firms' welfare. Proponents of antitakeover laws usually argue that the laws protect firms from detrimental hostile takeovers. However, in our model, takeovers can only enhance firm value and we still find anti-takeover laws may increase the expected firm value. Our theoretical prediction is also consistent with the empirical evidence (Armstrong et al., 2012) that financial reporting quality improves after the passage of antitakeover laws. Armstrong et al. (2012) interpret their finding as evidence of less private-information gathering in the equity market after the passage of antitakeover laws. Our theory provides an alternative explanation from the perspective of direct effects of information on takeover activities.

The remainder of the paper proceeds as follows. In Section 2 we provide a review of the related literature. In Section 3 we present the main model setup and analyze the acquirer's bidding strategy. We then examine the equilibria and analyze the optimal informationquality levels that maximize the current shareholders' expected payoff and the expected firm value, respectively. In Section 4, we examine the impact of antitakeover laws. Section

5 examines two extensions of the model. Section 6 concludes and discusses the empirical implications of our results. All proofs are in the Appendix.

\section{Related Literature}

Our paper fits in a broad literature that examines the "decision-usefulness" of accounting information. Along this line, a large strand of existing studies focus on exchange economy settings in which firm value is exogenously given and invariant to the accounting reporting system (for example, Lambert, Leuz, and Verrecchia, 2007). In contrast, in our paper the firm value is affected by current shareholders' information choice, and at the same time, the 
current shareholders' own constraints prevent them from choosing the optimal decision for firm value. Studies about the production effect of accounting information either use standard agency models (for example, Gigler and Hemmer, 2001; Chen, Hemmer, and Zhang, 2007) or real-effect models (for example, Kanodia and Lee, 1998). Our paper differs from these two approaches because, first, in contrast to typical agency models, the interest of the principal (the current shareholders) is not fully aligned with the firm value maximization in our model, and the manager is not the only pundit in the economy; second, in real-effect models, the information users only indirectly affect firm value through market pricing, while in our model the information users directly affect firm value by their merger and acquisition decisions.

Our result of the imperfect optimal-information precision echoes other studies with similar conclusions in different settings. For example, Kanodia, Singh, and Spero (2005) show that some degree of accounting imprecision can be value-enhancing in a setting with information asymmetry regarding investment profitabilities. Arya, Glover, and Sunder (1998) show that noisy signals (allowing earnings management by opportunistic managers) may be beneficial to owners who lack commitment. Arya and Mittendorf (2011) find that more detailed information may not always be beneficial in evaluating managers' performance given career concerns. Arya, Glover, and Sivaramakrishnan (1997) study a budget center's information precision decision as a commitment device, and show that a coarser-than-necessary information system can maximize its expected profit. Fan and Zhang (2012) show that, when a firm can control the quality of accounting information with some cost, optimal accounting policies aggregate underlying information and have a conservative bias. Bertomeu, Beyer, and Dye (2011) examine the interaction between a firm's disclosure policy and its capital structure and find that more expansive voluntary disclosure does not lead to a lower cost of capital. Our study contributes to this literature by examining the endogenous information quality in a corporate governance setting through the takeover market, as well as by analyzing the interaction of accounting information quality and governance mechanisms.

We also contribute to the studies on antitakeover laws and provisions. For example, DeAngelo and Rice (1983) test several explanations for antitakeover amendments and find weak support for the hypothesis that antitakeover laws benefits incumbent management. Comment and Schwert (1995) study the effect of antitakeover policies from 1975 to 1991 and find that antitakeover measures such as poison pill rights, control share laws, and business combination laws did not systematically deter takeovers. They also find that poison pills and control share laws are reliably associated with higher takeover premiums for selling shareholders. A recent study by Heron and Lie (2015) also finds similar evidence by examining the outcomes of unsolicited takeover attempts from 1985 to 2009. They find that poison pills 
lead to increased takeover premiums, but do not reduce takeover completion rates. Cremers and Ferrell (2014) find that after the Delaware Supreme Court's seminal decision in 1985, which judicially validated the adoption of a poison pill, the increase in shareholder rights is significantly associated with higher firm values. Although numerous empirical research studies antitakeover laws, the consequences of antitakeover laws remain an underexplored area in analytical research, and our study is among the first to provide theoretical insight on this topic.

Our paper is also related to the broad literature on the role of various corporate control mechanisms in the presence of information asymmetry among different parties. Langberg, Kumar, and Sivaramakrishnan (2012) study managers' voluntary disclosure decisions when an efficient market for corporate control influences their investment decisions. Baldenius, Melumad, and Meng (2014) examine the endogenous information environment and board composition, and the effects on CEO bias and investment efficiency. Caskey, Nagar, and Petacchi (2010) examine the role of an independent audit committee that attempts to remove the bias in a manager's reports, but may introduce its own bias into the reporting. Laux (2008) and Drymiotes (2007) analyze the effect of board independence and show that less independent boards can be more efficient. Laux and Laux (2009) examine the board of directors' strategies for setting CEO incentive pay and overseeing financial reporting and the effects on the level of earnings management. Our study adds to this literature by examining the disciplinary role of the takeover market in the presence of information uncertainty regarding the target.

\section{The Main Model}

\subsection{Model Setup}

We consider a two-period model with dates $t=0,1$, and 2. At date 0 , the current shareholders choose the quality of the financial reporting system, $d \in\left[\frac{1}{2}, 1\right]$. The quality represents the precision of the noisy signal generated by the financial reporting system, which we will elaborate soon. After $d$ is determined, an incumbent manager makes an effort $e$ that affects the firm's future value $v$. The firm value is binary, $v \in\{0,1\} .{ }^{5}$ For convenience, we refer to the manager as "he." The manager's effort is not observable. For simplicity, we assume that

\footnotetext{
${ }^{5}$ The binary outcome assumption simplifies the model and allows us to perform a more comparative statics analysis of our results. We have also examined a continuous-outcome setting and find that, though no closed-form solutions can be obtained due to the complexity of the payoff function, the main effects in the binary setting still exist in the continuous setting. The analysis is available upon request.
} 
$e \in[0,1]$. The cost of the manager's effort is a convex function, $\frac{1}{2} e^{2}$. If the manager shirks, the expected value of the firm will be lower. Specifically, we assume that the probability of generating a high firm value $(v=1)$ is $e($ i.e., $\operatorname{prob}(v=1 \mid e)=e)$, and the probability of a low firm value $(v=0)$ is $1-e$ (i.e., $\operatorname{prob}(v=0 \mid e)=1-e)$.

At date 1 , the firm value $v$ is privately observed by the current shareholders. Outsiders do not observe the firm value, but receive a noisy public signal $y$ about the firm value, which can be interpreted as a signal generated from the financial reporting system. ${ }^{6}$ The signal is binary, $y \in\{G, B\}$, where $G$ represents a good signal and $B$ represents a bad signal. The information quality of the financial reporting system determines the information properties of the signal. We assume that:

$$
\begin{aligned}
& \operatorname{prob}(y=G \mid v=1)=\operatorname{prob}(y=B \mid v=0)=d, \\
& \operatorname{prob}(y=B \mid v=1)=\operatorname{prob}(y=G \mid v=0)=1-d .
\end{aligned}
$$

That is, a higher quality information system produces a more informative signal.

At date 2, a potential acquirer makes an offer $p$ to the current shareholders. For convenience, we use "she" to refer to the acquirer. The takeover creates a synergy value of $v_{0}$, $0<v_{0}<1$, and $v_{0}$ is common knowledge and independent of the current firm value $v{ }^{7}$ The synergy value may come from improved operating efficiency, reduced capital investment, tax benefit, or market power (Bradley et al., 1988; Hayn, 1989; Kim and Singal, 1993; Fee and Thomas, 2004; Devos et al., 2009, etc.). If the takeover succeeds, the new firm value becomes $v+v_{0}$. If the takeover fails, the firm value remains to be $v$.

The synergy value $v_{0}$ is commonly known, and we assume that the acquirer and the current shareholders split the synergy value. Specifically, we assume that the acquirer is able to obtain $\gamma$ share of synergy value after takeover, and the current shareholders obtain

\footnotetext{
${ }^{6}$ We assume that the current shareholders obtain the perfect information about firm value for simplicity. A variation of our model could assume that shareholders observe a noisy signal about firm value, but the acquirer receives a less precise signal than what shareholders observe. Our main results are robust to this variation.

${ }^{7}$ In our model, we assume that the synergy value from takeover is independent of the target firm value. This assumption can be relaxed to allow asymmetric synergy values in high- and low-value firms (i.e., $v_{0}$ depends on $v$ ). For instance, it is possible that the acquirer is able to improve the firm value more in a badly managed firm than in a well managed firm. Our results remain robust as long as the synergy value through takeover does not overwhelm the prior firm value generated by management effort (i.e., $\left.v_{0}<1\right)$. If the synergy value is so large that it is greater than the maximum firm value through management effort, the impact of effort becomes negligible and only takeover efficiency matters, at which point perfect information quality is desirable; however, the case of a very huge synergy value is unrealistic and extreme. A detailed analysis is available upon request.
} 


\begin{tabular}{rccc}
$t=0$ & $t=1$ & $t=2$ \\
\hline $\begin{array}{c}\text { The current } \\
\text { shareholders } \\
\text { choose } d .\end{array}$ & $\begin{array}{c}\text { The manager } \\
\text { chooses } e .\end{array}$ & $\begin{array}{c}\text { Firm value } v \\
\text { is privately observed. } \\
\text { Signal } y\end{array}$ & $\begin{array}{c}\text { The acquirer } \\
\text { offers } p .\end{array}$ \\
& is publicly observed. & $\begin{array}{c}\text { Shareholders tender, } \\
\text { takeover succeeds } \\
\text { or fails. }\end{array}$
\end{tabular}

Figure 1: Timeline.

$1-\gamma$ share of synergy value. ${ }^{8}$

The manager enjoys a private benefit $m$ if the firm is not taken over. If the takeover succeeds, the incumbent manager is deprived of his private benefit. That is, in our main model, the manager is motivated to exert effort purely through the private benefit of control. ${ }^{9}$ It is reasonable to assume that the manager's private benefit is smaller than the synergy value from the takeover; i.e., $0<m<v_{0}$. By this assumption, we focus on takeover activities that are socially beneficial; otherwise, if $m>v_{0}$, it would be questionable whether takeover is socially optimal.

The acquirer makes the bidding offer based on her belief about the target value. If the current shareholders accept the offer, the takeover is successful; otherwise, the takeover fails. Figure 1 summarizes the timeline of our model.

\footnotetext{
${ }^{8} \gamma$ can be interpreted as the relative bargaining power over the synergy value created by the acquisition. A merger/acquisition agreement is often the result of negotiations between the acquirer and target shareholders (Betton, Eckbo, and Thorburn, 2008; Aktas, Bodt, and Roll, 2010). In our model we assume the synergy value is commonly known, and therefore bargaining over the synergy value is not affected by the information asymmetry over the target firm's current value. Synergy values usually come from increased sales, improved production efficiency, combined talent and technology, or cost reduction, and so forth, and the synergy gains are not necessarily contingent on the information asymmetry about the current firm value of the target. Bargaining over these synergy gains usually depends on which party is more critical in deriving these gains. For example, Ahern (2012) shows that the split of gains in a merger depends on the market power (or target scarcity) and the product market dependence (customer-supplier relationship) between the target and the acquirer. Therefore, in our model, we implicitly assume that the share of synergy value $(\gamma)$ between the acquirer and the target firm are determined by exogenous factors that are independent of the information asymmetry about the target firm's current value.

${ }^{9}$ In the main setting, we assume that $m$ is the manager's only benefit that compensates for his effort, as we want to concentrate on the disciplinary role of the takeover market instead of other incentive mechanisms. In Section 5 we show that our main results are robust when we introduce a performance-based compensation contract.
} 


\subsection{Acquirer's Bidding with Information Asymmetry}

In our model, the acquirer faces information asymmetry regarding the target's current fundamental value $v$. The current shareholders observe the true value before the acquirer makes the bidding offer. It is easy to see that the shareholders of a low-value firm will accept any offer no less than $p_{l} \equiv(1-\gamma) v_{0}$, and the shareholders of a high-value firm will accept any offer no less than $p_{h} \equiv 1+(1-\gamma) v_{0}$. The acquirer's payoff from the takeover, if successful, is $v+v_{0}-p$. We denote the acquirer's belief about the firm value being high given her conjecture about the managerial effort level and the signal to be $\hat{h}$, and the acquirer's expected payoff $\Pi_{r}$ is therefore given by

$$
\begin{aligned}
& \quad \Pi_{r}(p, \hat{h})=E\left[v \mid v+(1-\gamma) v_{0} \leq p\right]+v_{0}-p, \\
& \text { with } \quad \operatorname{Pr}(v=1)=\hat{h}, \operatorname{Pr}(v=0)=1-\hat{h}
\end{aligned}
$$

With the firm's value $v$ being binary (either 0 or 1 ), the acquirer will optimally offer either $p_{l}$, or $p_{h}$. Any other price is dominated. ${ }^{10}$

When the acquirer offers the high price $p_{h}$, both the high- and low-value firms' shareholders will accept the offer. In this case, the acquirer potentially suffers an overbidding loss if the acquired firm is a low-value firm, but the takeover always succeeds such that the acquirer always obtains the share of synergy value. When the acquirer offers $p_{l}$, only the low-value firms' shareholders will accept the offer. In this case, the acquirer does not overbid, but she cannot obtain the synergy value from acquiring a high-value firm. To maximize her expected payoff, the acquirer needs to consider the trade-off between the share of synergy value from taking over a high-value firm and the expected overbidding loss from taking over a low-value firm. The acquirer will offer $p_{h}$ only when her belief about high firm value is sufficiently high to avoid a potential overbidding loss; otherwise, the acquirer offers $p_{l}$, or is indifferent between offering $p_{l}$ and $p_{h}$.

If there were no accounting signals, the acquirer's belief would simply be her prior based on the conjectured effort level $\hat{h}=\hat{e}$. If her prior is high, she would bid $p_{h}$; if it is low, she would bid $p_{l}$; if her prior is at $\hat{h}=\hat{e}=\frac{1}{1+\gamma v_{0}}$, she would be indifferent between bidding $p_{h}$ and $p_{l}$. For our convenience, from now on we refer the acquirer's bidding strategy given no

\footnotetext{
${ }^{10}$ The reason is as follows. First, in order to induce the high-value-firm shareholders to tender, the acquirer only needs to offer exactly $1+(1-\gamma) v_{0}$. Any price above $1+(1-\gamma) v_{0}$ is not optimal for the acquirer, as it merely increases the takeover cost while yielding the same takeover outcome. In addition, the acquirer would not offer any price between $p_{h}$ and $p_{l}$. To see this, suppose the acquirer offers a price $p^{\prime}$ and $(1-\gamma) v_{0}<p^{\prime}<1+(1-\gamma) v_{0}$; in this scenario, only the low-value firms' shareholders accept $p^{\prime}$. However, the acquirer can be better off by reducing the offer price to $(1-\gamma) v_{0}$, which yields the same takeover outcome (i.e., successful takeover of a low-value firm) without an additional overbidding premium.
} 
signal to be her default bidding strategy.

Lemma 1 The acquirer's default bidding strategy without accounting signals is: bidding $p_{h}$ for $\hat{e}>\frac{1}{1+\gamma v_{0}}$; bidding $p_{l}$ for $\hat{e}<\frac{1}{1+\gamma v_{0}}$; and indifferent between $p_{h}$ and $p_{l}$ for $\hat{e}=\frac{1}{1+\gamma v_{0}}$.

With the accounting signals, the acquirer's strategy is now based on the updated belief after observing the signal, $\hat{h}(y) \equiv \operatorname{Prob}(v=1 \mid \hat{e}, y)$. Given the information structure in (1), we have:

$$
\begin{aligned}
\hat{h}(G) & =\frac{\hat{e} d}{\hat{e} d+(1-d)(1-\hat{e})}, \\
\hat{h}(B) & =\frac{\hat{e}(1-d)}{\hat{e}(1-d)+(1-\hat{e}) d} .
\end{aligned}
$$

To facilitate our discussion, we define $\alpha_{G}$ and $\alpha_{B}$ as the probability of offering a high price upon a good signal and a bad signal, respectively (i.e., $\alpha_{G}=\operatorname{Pr}\left(p_{h} \mid G\right)$ and $\alpha_{B}=\operatorname{Pr}\left(p_{h} \mid B\right)$ ). We have the following results.

Lemma 2 The acquirer's bidding strategy with accounting signals is as follows:

- When the information quality $d$ is low $\left(\frac{1}{2} \leq d<\frac{1-\hat{e}}{1-\hat{e}\left(1-\gamma v_{0}\right)}\right)$, the acquirer sticks to her default bidding strategy.

- When the information quality is high $\left(\frac{1-\hat{e}}{1-\hat{e}\left(1-\gamma v_{0}\right)} \leq d \leq 1\right)$, the acquirer revises her bidding strategy in the following way:

- If $\hat{e}>\frac{1}{1+\gamma v_{0}}$, then $\alpha_{G}=1$, and $\alpha_{B}=0$ or $0<\alpha_{B}<1$.

- If $\hat{e}<\frac{1}{1+\gamma v_{0}}$, then $\alpha_{G}=1$ or $0<\alpha_{G}<1$, and $\alpha_{B}=0$.

- If $\hat{e}=\frac{1}{1+\gamma v_{0}}$, then $\alpha_{G}=1$ and $\alpha_{B}=0$.

The results highlight the role of information quality in determining the acquirer's bidding strategy. When the signal is consistent with the prior, it is optimal for the acquirer to go with the prior and follow her default bidding strategy. When the signal contradicts the prior, it is optimal for the acquirer to go with the signal only when the information quality of the signal is sufficiently high. For example, when the prior is optimistic ( $\hat{e}$ is high), the acquirer's default strategy is to bid the high price. In this case, a contradicting bad signal can change the acquirer's default decision only if the signal is very precise. Similar intuition applies to the case when the prior is pessimistic ( $\hat{e}$ is low). 


\subsection{Equilibrium Analysis}

We first characterize the manager's equilibrium effort and the acquirer's equilibrium bidding strategy, taking as given the information quality $d$. We will later examine the optimal choices of information quality for the current shareholders and the firm value maximization, respectively.

A perfect Bayesian equilibrium of the manager's effort and the acquirer's bidding strategy, given the information quality, is defined as follows.

Definition 1 A set of strategies $\left(e^{*}, \alpha_{G}^{*}, \alpha_{B}^{*}\right)$ forms a perfect Bayesian equilibrium such that:

(1). The acquirer forms her belief about the manager's effort $\hat{e}$, and her optimal bidding strategy $\left(\alpha_{G}^{*}(\hat{e}), \alpha_{B}^{*}(\hat{e})\right)$ satisfies the bidding strategies specified in Lemma 2.

(2). The manager's optimal effort $e^{*}$ maximizes his own expected payoff, given the anticipated optimal bidding strategy of the acquirer $\left(\alpha_{G}^{*}(\hat{e}), \alpha_{B}^{*}(\hat{e})\right)$.

(3). The acquirer's belief is consistent with the manager's optimal effort, $\hat{e}=e^{*}$.

For any bidding strategy, a takeover fails when the acquirer offers a low price and the true value of the firm is high. Given the manager's effort $e$, the probability of takeover success, $\operatorname{Prob}[T]$, is

$$
\operatorname{Prob}[T]=1-e+e\left[d \alpha_{G}+(1-d) \alpha_{B}\right] .
$$

The manager's expected payoff for choosing an effort level of $e$ given the acquirer's bidding strategy, $\Pi_{m}\left(e, \alpha_{G}, \alpha_{B}\right)$, is thus given by:

$$
\Pi_{m}(e, \alpha, \beta)=(1-\operatorname{Prob}[T]) m-\frac{e^{2}}{2}=e \cdot\left(1-\left[d \alpha_{G}+(1-d) \alpha_{B}\right]\right) m-\frac{e^{2}}{2} .
$$

Given the acquirer's strategy, the manager's optimal effort that maximizes his expected payoff is

$$
e^{*}\left(\alpha_{G}, \alpha_{B}\right)=m-\left[d \alpha_{G}+(1-d) \alpha_{B}\right] m .
$$

The takeover market affects the manager's effort incentive in two ways. First, it disciplines the manager to make effort since a low-value firm is always taken over, as represented by the first term in (6). The manager is motivated to exert effort to reduce the probability of low firm value, and this reduces the takeover probability directly. Second, the takeover threat discourages the manager's effort when a high-value firm may also be taken over. This negative effect of the takeover market is represented by the second term, $-\left[d \alpha_{G}+(1-d) \alpha_{B}\right] m$, in (6). 
Notice that this negative effect is aggravated when the information quality $d$ increases or when the acquirer's bidding becomes more aggressive with a higher $\alpha_{G}$ or $\alpha_{B}$. This is because both higher information quality and aggressive bidding increase the chance of a successful takeover for the high-value firm and thus further discourages the managerial effort.

We find that not all bidding strategies in Lemma 2 are sustainable in equilibrium, because the acquirer's conjecture of the manager's effort must be consistent with the manager's optimal choice of effort. Our analysis shows that, in equilibrium, aggressive bidding strategies are not sustainable. In particular, we find that the acquirer will not bid the high price with certainty upon a good signal $\left(0<\alpha_{G}^{*}<1\right)$. This is because if she always bids the high price upon a good signal, the chance that a high-value firm is taken over becomes high, which significantly discourages the manager's effort. As a result, the expected firm value will be low, which cannot support the acquirer's belief of a high $\hat{e}$ to always bid the high price upon a good signal. Moreover, in equilibrium, the acquirer always bids a low price upon a bad signal, $\alpha_{B}^{*}=0$. This is because the acquirer is willing to bid a high price upon a bad signal only when the conjectured effort is high and the information quality is low (Lemma $2)$. The aggressive bidding $\left(\alpha_{B}^{*}>0\right)$ again discourages the manager's effort, and cannot be sustainable in equilibrium.

We list the three sustainable equilibria given the information quality $d$ and the manager's private benefit level $m$ as follows:

- (separating-price-bidding equilibrium) When $d=1$, the manager chooses $e^{*}=0$, and the acquirer chooses $\alpha_{G}^{*}=1$ and $\alpha_{B}^{*}=0 ;^{11}$

- (mixed-price-bidding equilibrium) When $m>\frac{1}{1+\gamma v_{0}}$ and $\frac{1}{2} \leq d<1$, or $m \leq$ $\frac{1}{1+\gamma v_{0}}$ and $1>d>\frac{1-m}{1-m+\gamma v_{0} m}$, the manager chooses $e^{*}=\frac{1-d}{1-d\left(1-\gamma v_{0}\right)}$, and the acquirer chooses $\alpha_{G}^{*}=\frac{1}{d} \frac{\gamma v_{0} d m-(1-d)(1-m)}{(1-d) m+\gamma v_{0} d m}$ and $\alpha_{B}^{*}=0$;

- (low-price-bidding equilibrium) When $m \leq \frac{1}{1+\gamma v_{0}}$ and $\frac{1}{2} \leq d \leq \frac{1-m}{1-m+\gamma v_{0} m}$, the manager chooses $e^{*}=m$, and the acquirer chooses $\alpha_{G}^{*}=\alpha_{B}^{*}=0$.

The conditions for these three different equilibria are mutually exclusive and exhaustive.

Given the sustainable equilibria, we summarize the comparative statics analysis about how the information quality affects the equilibrium effort and bidding strategy as follows.

\footnotetext{
${ }^{11}$ Notice that even though $\alpha_{G}^{*}=1$ appears in the separating-price-bidding equilibrium when $d=1$, we will never observe a good signal in that equilibrium, because the manager's effort incentive is completely eliminated and thus the firm value is always low, which will always result in a bad signal by the perfect information system.
} 
Proposition 1 The equilibrium manager effort $\left(e^{*}\right)$ is weakly decreasing in the information quality, and the probability of bidding a high price upon a good signal $\left(\alpha_{G}^{*}\right)$ in equilibrium is weakly increasing in the information quality; i.e.,

$$
\frac{\partial e^{*}}{\partial d} \leq 0, \quad \frac{\partial \alpha_{G}^{*}}{\partial d} \geq 0
$$

Proposition 1 indicates that the information quality brings a tradeoff. If the information is perfect (that is, when the separating-price-bidding equilibrium is the only sustainable equilibrium), takeover always succeeds and we have the most efficient takeover outcome. However, notice that the manager has an incentive to exert effort only when his effort can influence the likelihood of takeover success. With perfect information, the manager's incentive to exert effort is completely eliminated $\left(e^{*}=0\right)$, because the perfect information completely severs this channel of influence.

In contrast to the perfect-information case, if the information is very noisy and the manager's private benefit is relatively small (i.e., when both $m$ and $d$ are low), the acquirer will never bid the high price, which leads to the low-price-bidding equilibrium. This is because a low $m$ indicates that the manager's incentive to work is low and, in addition, the acquirer's prior is low. With a low prior and a low-quality signal that is not precise enough to sway her opinion, the acquirer will not offer the high price. In this case, the takeover market has the strongest disciplinary role in the sense that only a low-value firm will be taken over, and there is no negative impact on the manager's effort. Because the acquirer is discouraged from bidding the high price, the probability of a socially-efficient takeover decreases. In this equilibrium, a higher information quality changes neither the manager's effort nor the acquirer's bidding strategy (i.e., $\frac{\partial e^{*}}{\partial d}=0, \frac{\partial \alpha_{G}^{*}}{\partial d}=0$.)

While a low $m$ indicates a low prior for the acquirer, the acquirer may occasionally offer the high price upon a good signal when the signal is relatively more precise (mixed-pricebidding equilibrium). In this case, both the effort and the bidding strategy depend on the information quality. In general, as the information quality increases, the acquirer is less concerned about overbidding upon a good signal, and more likely to bid the high price (i.e., $\frac{\partial \alpha_{G}^{*}}{\partial d}>0$ ), which leads to more efficient takeover outcomes. At the same time, since the manager is more likely to lose his private benefit even though he works hard, higher information quality negatively impacts the manager's effort incentive and discourages the manager's effort (i.e., $\frac{\partial e^{*}}{\partial d}<0$ ).

Our analysis may provide some interesting insights into takeover markets. Some previous studies have also shown that the takeover market is an effective corporate governance mech- 
anism to discipline the manager. However, such studies usually argue that the reason why the takeover market can discipline managers is because acquirers are more likely to take over firms with inefficient managers, and in such cases, the more precise the information about the manager's performance, the larger the disciplining effect. In contrast, our study shows a different intuition; that is, the takeover market motives the manager to work hard (because a low-value firm is taken over for sure), but only if the accounting signal is not perfect. If the accounting signal is so accurate that takeovers almost always succeed, the manager loses his incentive to exert effort because the takeover threat is disconnected from the manager's performance.

\subsection{Optimal Information Quality}

In this section we examine the optimal choices of information quality that maximize the current shareholders' payoff and the firm value, respectively. The firm value maximization and the current shareholders' expected payoff maximization are not fully aligned in the presence of the takeover market. While both perspectives are broadly concerned about the trade-off between managerial effort efficiency and takeover efficiency, the magnitude of takeover efficiency differs: the current shareholders only gain a share of the synergy value upon a successful takeover, whereas they also have the incentive to obtain an overbidding premium from the acquirer. As a consequence, the optimal information quality to maximize the firm value, denoted by $d_{v}^{*}$, is different from the optimal quality that maximizes the current shareholders' payoff, denoted by $d_{s}^{*}$. We will analyze both optimal information quality levels.

We denote $\Pi_{v}\left(e^{*}, \alpha_{G}^{*}, \alpha_{B}^{*}\right)$ to be the expected firm value and $\Pi_{s}\left(e^{*}, \alpha_{G}^{*}, \alpha_{B}^{*}\right)$ to be the current shareholders' expected payoff. The expected firm value is the current firm value plus the expected total synergy value from a successful takeover. In contrast, the current shareholders' expected payoff consists of three parts: the current firm value, the expected share of synergy value from a successful takeover, and the overbidding premium when the acquirer offers a high price but the firm value is low. Formally, the expected firm value and the current shareholders' expected payoff are, respectively,

$$
\begin{aligned}
\Pi_{v}\left(e^{*}, \alpha_{G}^{*}, \alpha_{B}^{*}\right)= & E\left[v \mid e^{*}, \alpha_{G}^{*}, \alpha_{B}^{*}\right]+\operatorname{Prob}\left(T \mid e^{*}, \alpha_{G}^{*}, \alpha_{B}^{*}\right) v_{0}, \\
\Pi_{s}\left(e^{*}, \alpha_{G}^{*}, \alpha_{B}^{*}\right)= & E\left[v \mid e^{*}, \alpha_{G}^{*}, \alpha_{B}^{*}\right]+\operatorname{Prob}\left(T \mid e^{*}, \alpha_{G}^{*}, \alpha_{B}^{*}\right)(1-\gamma) v_{0} \\
& +\operatorname{Prob}\left(O T \mid e^{*}, \alpha_{G}^{*}, \alpha_{B}^{*}\right) \cdot 1 .
\end{aligned}
$$


In the payoff functions above, $\operatorname{Prob}\left(T \mid e^{*}, \alpha_{G}^{*}, \alpha_{B}^{*}\right)=1-e^{*}+e^{*} d \alpha_{G}^{*}$, which is the probability of success given the equilibrium effort and bidding strategy. $\operatorname{Prob}\left(O T \mid e^{*}, \alpha_{G}^{*}, \alpha_{B}^{*}\right)$ is the probability of overbidding in successful takeover, which occurs only when a low-value firm generates a good signal and receives a high bidding price. Substituting the equilibrium effort and the bidding strategy into the above payoff functions, we can see that the information quality affects the payoffs through each of the three components as stated in Lemma 3.

Lemma 3 Given the equilibrium $e^{*}, \alpha_{G}^{*}$, and $\alpha_{B}^{*}$, increasing the information quality has the following effects:

- it decreases the current firm value, $E\left[v \mid e^{*}, \alpha_{G}^{*}, \alpha_{B}^{*}\right]$;

- it increases the probability of takeover success, $\operatorname{Prob}\left(T \mid e^{*}, \alpha_{G}^{*}, \alpha_{B}^{*}\right)$;

- it has a non-monotone effect on the probability of overbidding, with $\operatorname{Prob}\left(O T \mid e^{*}, \alpha_{G}^{*}, \alpha_{B}^{*}\right)$ maximized at $d^{0} \equiv \frac{2-m}{2-m+m \gamma v_{0}}$.

Increasing the information quality reduces the equilibrium effort, which means the firm value is more likely to be low, and therefore the current firm value decreases as the information quality increases. The low current firm value leads to an overall increase in the takeover success probability.

As for the impact on the probability of overbidding, there are two effects. Increasing the information quality reduces the likelihood of misreporting a high signal for a low-value firm, which directly reduces the probability of overbidding; however, the acquirer also bids more aggressively as the information quality increases, therefore increasing the probability of overbidding. The trade-off between these two effects leads to an interior level of $d$ that maximizes the overall probability of overbidding.

From Lemma 3, it is clear that the information quality affects the takeover efficiency and current firm value in the exact opposite directions. We first consider the optimal information quality choice for firm value maximization. The choice of optimal information quality that maximizes the expected firm value depends on the trade-off between marginal effects on the current firm value as determined by the manager's effort and the expected synergy value from successful takeovers.

Proposition 2 When the synergy value is small $\left(v_{0} \leq \frac{1}{2}\right)$, we have $d_{v}^{*} \in\left[\frac{1}{2}, \frac{1-m}{1-m+m \gamma v_{0}}\right]$; when the synergy value is large $\left(v_{0}>\frac{1}{2}\right)$, we have $d_{v}^{*}=\frac{2 v_{0}-m}{2 v_{0}-m+m \gamma v_{0}}$. 
The results in Proposition 2 suggest that the synergy value $\left(v_{0}\right)$ is the key determinant of the optimal information quality to maximize the expected firm value. When the synergy value is small, it is more important to motivate the incumbent manager to work hard to improve the current firm value than to obtain the potential synergy value from a takeover, and thus the optimal information quality remains low to mitigate the takeover threat to the manager. On the other hand, when the synergy value is large, it is more important to improve the takeover efficiency to realize the synergy value from a takeover, and thus it is value-maximizing to have a higher information quality level in order to improve the chance of takeover success (notice that with $v_{0}>\frac{1}{2}$, we have $d_{v}^{*}=\frac{2 v_{0}-m}{2 v_{0}-m+m \gamma v_{0}}>\frac{1-m}{1-m+m \gamma v_{0}}$ ).

However, a perfect information system is never optimal for firm value maximization regardless of how large the synergy value. As previously mentioned, perfect information quality completely destroys the manager's effort incentive, and as a result, the current firm value will always be low. Although with a perfect information system, the firm can fully realize the synergy value as the takeover always succeeds, on the margin, changing information quality has almost no effect on takeover efficiency when the information quality is close to perfect. However, lowering the information quality to a less-than-perfect level has a strictly positive effect on the manager's effort and thus increases the total firm value. Therefore, it is always worthwhile to lower the information quality to a less-than-perfect level for firm value maximization.

For the current shareholders, the above trade-off also applies, but compared with the firm value maximization, the impact of changing information quality on the current shareholders' expected payoff differs in the following two aspects. First, the current shareholders only receive partial benefit $(1-\gamma)$ from the synergy value after a successful takeover. Second, the current shareholders receive an overbidding premium from the acquirer, which is a wealth transfer from the acquirer (the future shareholder) to the current shareholders and not part of the expected firm value. We have the following proposition regarding the optimal information quality to maximize the shareholders' payoff.

Proposition 3 When the synergy value is small $\left(v_{0} \leq \frac{1}{2}\right)$, we have $d_{s}^{*}, d_{v}^{*} \in\left[\frac{1}{2}, \frac{1-m}{1-m+m \gamma v_{0}}\right]$; when the synergy value is large $\left(v_{0}>\frac{1}{2}\right)$, we have $d_{s}^{*}<d_{v}^{*}<1$.

Similar to its role in firm value maximization, the synergy value is a key determinant in the current shareholders' optimal information quality choice. When the synergy value is small $\left(v_{0} \leq \frac{1}{2}\right)$, motivating the manager to increase the existing firm value is more critical, and thus the shareholders choose the same low-range information quality level that sustains the low-price-bidding equilibrium so that the takeover threat to the manager is minimized 
(i.e., $\left.d_{s}^{*}, d_{v}^{*} \in\left[\frac{1}{2}, \frac{1-m}{1-m+m \gamma v_{0}}\right]\right)$. In this case, the current shareholders care more about the managerial effort (and thus the current firm value) than either the potential synergy value or the overbidding premium. In fact, in this equilibrium the shareholders do not enjoy the overbidding premium.

When the synergy value is sufficiently large $\left(v_{0}>\frac{1}{2}\right)$, the information quality choice for the current shareholders depends on the share of surplus that they may obtain from a successful takeover and the manager's private benefit. Since the current shareholders do not enjoy the full benefit of the synergy value from a successful takeover, they lack the incentive to improve the information quality to the level of $d_{v}^{*}$, as they care less about takeover efficiency (i.e., $d_{s}^{*}<d_{v}^{*}<1$ ). The impact on the overbidding premium from the information quality choice, however, is not so obvious. On the one hand, higher information quality increases the overbidding premium because it increases a good signal's informativeness, and thus the acquirer bids more aggressively upon a good signal. However, on the other hand, higher information quality may reduce the expected overbidding premium, because the overall probability of observing the good signal for a low-value firm is reduced. The information quality that maximizes the overbidding premium alone, $d^{0}$ in Lemma 3 , is higher than the optimal information quality that maximizes the expected firm value (i.e., $d^{0}>d_{v}^{*}$ ). That is, to capture more overbidding premium, the current shareholders would increase the information quality higher than the socially optimal level. However, once considering the impact of information quality on both the synergy value and the overbidding premium, the current shareholders are better off overall by choosing a lower level of information quality than $d_{v}^{*}$, because the impact of the partial surplus from the synergy value dominates.

\section{Antitakeover Laws}

The takeover market can be influenced by antitakeover laws. The first generation of antitakeover laws started in the U.S. in 1968 with the Williams Act. In the mid-to-late 1980s and 1990s, many states introduced the second and third generations of antitakeover statutes with even more stringent regulations on takeovers. Antitakeover laws primarily took three forms: control-share-acquisition laws, fair-price laws, and business-combinations laws (Bertrand and Mullainathan, 2003; Cheng, Nagar, Rajan, 2004). ${ }^{12}$

\footnotetext{
${ }^{12}$ Control-share-acquisition laws provide the holders of shares not held by the acquirer the right to decide whether the acquirer's shares have voting right in takeover. Fair-price laws require the acquirer to pay a fair price for the shares for takeover purposes. The fair price is calculated using rules such as the maximum the acquirer paid for shares acquired in the preceding two-year period. In essence, the fair-price laws impede a takeover by forcing the acquirer to pay a high price for shares. Finally, business-combination laws prohibit
} 
In this section, we examine the impact of antitakeover laws on the optimal informationquality level that maximizes the current shareholders' payoff. Moreover, we investigate the effects of antitakeover laws on the expected firm value, taking into account the current shareholders' adjustment of optimal information quality in response to antitakeover laws. Following prior studies such as Cheng et al. (2004), we treat the passage of antitakeover laws as an exogenous shock to the corporate takeover market. We model the effect of antitakeover laws by a decrease of the acquirer's share of surplus from synergy value; i.e., $\gamma$ is lower after antitakeover laws are imposed. Antitakeover laws either weaken the acquirer's voting power thereby lowering her bargaining power (through control-share-acquisition laws), or directly increase the offer price (through fair-price law), or reduce the potential divergence of future firm value by the acquirer (through business-combination laws). All these effects are consistent with a decrease in $\gamma$ in our model.

\subsection{Antitakeover Laws and Information Quality}

We now examine the impact of antitakeover laws on the optimal information quality choice for the current shareholders. Recall that our analysis in the last section shows cases in which the optimal information quality is in the low range to sustain the low-price-bidding equilibrium, $d_{s}^{*} \in\left[\frac{1}{2}, \frac{1-m}{1-m+m \gamma v_{0}}\right]$. In these cases, both the equilibrium effort $\left(e^{*}=m\right)$ and bidding strategy $\left(\alpha_{G}^{*}, \alpha_{B}^{*}=0\right)$ are insensitive to the information quality, as well as to the share of synergy value, and thus the antitakeover laws do not play any active role. Therefore, in this section we exclude these cases. We focus instead on cases in which antitakeover laws have an impact, which happens in the following two scenarios when $v_{0}>\frac{1}{2}$ :

- A1: when the acquirer's share of synergy value is large and the manager's private benefit is also large, the optimal information quality is at the lower bound; i.e., $d_{s}^{*}=\frac{1}{2}$.

- A2: when the acquirer's share of synergy value is small, the optimal information quality is an interior solution, $d_{s}^{*}=\frac{2 v_{0}-m-m \gamma v_{0}}{2 v_{0}-m+m \gamma^{2} v_{0}^{2}}$.

Scenario A1 prevails when the acquirer's share of synergy value, $\gamma$, is large, and the manager's private benefit, $m$, is also relatively large. As a result, the acquirer's conjectured effort level is high and she is more likely to offer a high price regardless of information quality (the mixed-price equilibrium sustains). In this scenario, the current shareholders are more

the acquirer from specified transactions, such as sales of assets, mergers, and relational transactions, for a number of years unless the board votes otherwise. Overall these antitakeover legislations make takeovers more difficult and costly to acquirers with the aim of deterring takeovers (Romano, 1992). 
concerned about the negative effect on the effort from the acquirer's aggressive bidding, and optimally choose the lowest information quality, $d_{s}^{*}=\frac{1}{2}$. That is, denote $d_{s}^{* *}$ to be the current shareholders' optimal choice of information quality after the passage of antitakeover laws. Thus, in scenario $\mathbf{A} \mathbf{1}$ we have $d_{s}^{* *}=d_{s}^{*}=\frac{1}{2} \cdot{ }^{13}$

Scenario A2 prevails when the acquirer's share of synergy value, $\gamma$, is relatively small. In this scenario the shareholders optimally choose an interior level of information quality above the minimum level. After the passage of antitakeover laws, the acquirer's share of synergy value is reduced, and she bids less aggressively as the expected payoff from the successful takeover becomes smaller. Consequently, the negative effect of increasing information quality on managerial effort is mitigated. Therefore, the current shareholders have stronger incentives to increase the information quality after the passage of antitakeover laws to encourage the acquirer to bid more aggressively. Moreover, the passage of antitakeover laws also directly increases the shareholders' share of synergy value, which gives them more incentive to increase the information quality. Overall, the optimal information-quality level will increase after the passage of antitakeover laws, $d_{s}^{* *}>d_{s}^{*}>\frac{1}{2}$.

To summarize, we have the following proposition.

Proposition 4 After the passage of antitakeover laws, the current shareholders' optimal information quality level weakly increases; i.e., $d_{s}^{* *} \geq d_{s}^{*}$.

The results in Proposition 4 are consistent with the empirical evidence that financial reporting quality improves after the adoption of antitakeover laws. Armstrong et al. (2012) suggest that their finding of more informative financial statements after the passage of antitakeover laws is consistent with less private-information gathering in the equity market. We provide an alternative explanation for the change of information environment. That is, the current shareholders endogenously increase the information quality of financial reporting in response to the passage of antitakeover laws. Our analysis focuses on the direct impact of information on the takeover market, as well as the manager's effort incentives with the presence of a takeover threat.

\footnotetext{
${ }^{13} \mathrm{As}$ long as the antitakeover laws do not reduce the acquirer's share of synergy value significantly, and the manager's private benefit is sufficiently large, the prevailing scenario does not change after the anti-takeover laws. If the scenario changes after such laws, for example, if antitakeover laws reduce the acquirer's share of synergy from $\gamma$ to $\gamma^{\prime}$ such that A1 holds with $\gamma$ while A2 holds with $\gamma^{\prime}$, we can consider it a combination of A1 and A2. The result is still consistent with our overall conclusion in Proposition 4 . Discussing all of these possibilities does not add new insights into our results, and therefore we stick to the cases in which each scenario still holds after the passage of antitakeover laws throughout the discussion.
} 


\subsection{Economic Consequences of Antitakeover Laws}

Taking into consideration that the current shareholders may adjust the information quality in response to antitakeover laws, we now examine the consequences of such laws on managerial effort, takeover efficiency, the current shareholders' welfare, and firm value. We have the following results regarding the antitakeover laws' impacts.

Proposition 5 When the current shareholders are able to adjust the information quality level, the adoption of antitakeover laws results in the following consequences:

- the current shareholders' expected payoff always increases;

- in scenario $\boldsymbol{A 1}$, the manager's effort increases, the probability of takeover decreases, and the expected firm value's decreases after antitakeover laws;

- in scenario A2, the manager's effort decreases, the probability of takeover increases, and the expected firm value increases after antitakeover laws.

The current shareholders' payoff always increases after the passage of antitakeover laws, because they now enjoy a larger share from synergy value through antitakeover protections. The expected firm value, in contrast, may either increase or decrease depending on the current shareholders' adjustment of information quality in response to antitakeover laws.

In scenario A1, the current shareholders do not change the information quality after the passage of antitakeover laws. With the adoption of such laws and the unchanged information quality, the manager's effort increases because the acquirer bids less aggressively. Although the overall takeover efficiency nonetheless decreases since the acquirer bids less aggressively, the firm value is more likely to be high, which in turn reduces the expected synergy value from takeover. The expected total firm value is determined by a tradeoff between the decrease in the expected synergy value because of a less efficient takeover and the increase in the current firm value due to higher managerial effort. In this scenario, because the synergy value is relatively large, the passage of antitakeover laws has a much larger negative effect on the expected synergy value compared with the positive impact on the current firm value through managerial effort. The expected total firm value therefore decreases after the passage of antitakeover laws.

In scenario A2, since antitakeover laws increase the current shareholders' share in synergy value, the shareholders care more about the synergy value from a successful takeover than the current fundamental firm value. Therefore the current shareholders optimally increase the information quality to motivate more aggressive bidding by reducing the acquirer's concern 
for overbidding. As a result, the overall probability of takeover increases and the manager's effort decreases. Since the current shareholders choose a higher information quality level, their choice is more aligned with firm value maximization, and therefore the expected total firm value increases.

It is often argued that antitakeover laws deter takeovers, thereby insulating managers from the takeover market and aggravating management entrenchment. Empirical studies, however, do not find strong evidence on the deterrence effect of antitakeover laws on takeovers. ${ }^{14}$ Our results in Proposition 5 may provide a potential explanation for this empirical observation, as we find that the takeover frequency (efficiency) may either increase or decrease, depending on the endogenous information quality choice after the passage of antitakeover laws. Some empirical evidences show that firms' information quality increases and, at the same time, overall takeover frequency increases upon the passage of antitakeover laws (Armstrong et al., 2012; Comment and Schwert, 1995), which is consistent with our model's predictions of scenario A2. Furthermore, we also show that the acquirer's bidding is more aggressive when shareholders increase information quality after antitakeover laws, consistent with the finding in Comment and Schwert (1995) that antitakeover laws are associated with a significant increase in takeover premiums (i.e., the price paid above the target's firm value).

Moreover, our analysis may offer some insight on the debate about whether antitakeover legislation enhances or destroys shareholders' welfare. ${ }^{15}$ It is interesting that our analysis provides different implications from conventional wisdom in regards to antitakeover laws' impact on firms' welfare. Proponents of antitakeover laws usually argue that the laws protect firms from detrimental hostile takeovers. However, in our model, takeovers can only enhance firm value (for which the conventional wisdom suggests that anti-takeover laws reduce the firm value), and we still find that antitakeover laws may increase the expected firm value. The higher expected firm value is actually due to the fact that the current shareholders increase the information quality in response to antitakeover laws to improve takeover efficiency.

Our results highlight the different impact of antitakeover laws on the the current shareholders' payoff and the expected firm value. Moreover, the impact of antitakeover laws on the expected firm value depends on the changes of the firm's information environment in response to the passage of such laws.

\footnotetext{
${ }^{14}$ For example, Ambrose and Megginson (1992) and Bhagat and Jefferis (1993) find little evidence that antitakeover defenses reduce takeover activities.

${ }^{15}$ See Straska and Waller (2014) for a survey of studies in antitakeover legislations. Some argue that antitakeover provisions result in losses because antitakeover provisions protect managers from the market's disciplining influence and impede valuable takeover enhancement. Others argue that antitakeover provisions improve shareholders' welfare despite the decrease of takeover probability, because shareholders may gain a higher premium from more bargaining power in a takeover.
} 


\section{Extensions}

\subsection{Generalized Information Systems}

In this section, we consider a more general assumption about the information system, allowing for different information quality levels for high- and low-value firms. We assume that $\operatorname{prob}(y=B \mid v=0)=d_{0}$ and $\operatorname{prob}(y=G \mid v=1)=d_{1}$, where $d_{0} \in\left[\frac{1}{2}, 1\right]$ and $d_{1} \in\left[\frac{1}{2}, 1\right]$ can be different. With this general information structure, we can define the likelihood ratios for a good signal and a bad signal as $L_{G} \equiv \frac{\operatorname{prob}(G \mid v=1)}{\operatorname{prob}(G \mid v=0)}=\frac{d_{1}}{1-d_{0}}$ and $L_{B} \equiv \frac{\operatorname{prob}(B \mid v=1)}{\operatorname{prob}(B \mid v=0)}=\frac{1-d_{1}}{d_{0}}$, respectively. An increase in the precision of signals $\left(d_{0}\right.$ or $\left.d_{1}\right)$ increases the likelihood ratio for a good signal, but decreases the likelihood ratio for a bad signal. We can characterize the informativeness of the information system by the likelihood ratios. A more informative system suggests a higher likelihood ratio for a good signal, $L_{G}$, or a lower likelihood ratio for a bad signal, $L_{B}$. A perfectly informative system yields $L_{G}=\infty$ and $L_{B}=0$.

For any conjectured effort level $\hat{e}$, the acquirer's updated belief about a high firm value upon a signal can be written as $h(G)=\frac{\hat{e} L_{G}}{\hat{e} L_{G}+(1-\hat{e})}$ and $h(B)=\frac{\hat{e} L_{B}}{\hat{e} L_{B}+(1-\hat{e})}$. It is easy to see that the acquirer's belief depends on the likelihood ratios $L_{G}$ and $L_{B}$, instead of on the individual $d_{0}$ or $d_{1}$. As in the main setup, in equilibrium the acquirer will never bid the high price upon a bad signal, because it is not sustainable to support the conjectured effort level.

Among the sustainable equilibria, the acquirer may be willing to offer the high price with some probability upon observing a good signal. When the likelihood ratio for a good signal $L_{G}$ increases, the acquirer's belief regarding high firm value also increases, and the acquirer will bid more aggressively upon a good signal. As a result, the likelihood ratio for a good signal $L_{G}$ directly affects the acquirer's bidding strategy and the manager's effort in equilibrium. The basic intuition from our main analysis still holds here: increasing the informativeness of the system (in terms of a higher likelihood ratio for a good signal) improves the overall takeover efficiency, but discourages the manager's effort. Similar to that in the main setup, we can show that a perfect information system $\left(L_{G}=\infty\right)$ is not optimal for either the current shareholders or the firm value maximization.

With the generalized information structure, the optimal levels of $d_{0}$ and $d_{1}$ that maximize the current shareholders' payoff or the firm value are not uniquely identified. Rather, we find that the optimal information system only depends on the likelihood ratio upon the good signal, $L_{G}$. Specifically, there exists an optimal likelihood ratio $L_{G s}^{*}$ that maximizes the current shareholders' payoff, and an optimal likelihood ratio $L_{G v}^{*}$ that maximizes the firm value. ${ }^{16}$

\footnotetext{
${ }^{16}$ Proposition 6 shows the results when the optimal likelihood ratios have interior solutions. We may
} 
Proposition 6 The current shareholders' payoff is maximized when the likelihood ratio satisfies $L_{G s}^{*} \equiv \frac{d_{1 s}^{*}}{1-d_{0 s}^{*}}=\frac{2 v_{0}-m\left(1+\gamma v_{0}\right)}{m \gamma v_{0}\left(1+\gamma v_{0}\right)}$, and the total firm value is maximized when the likelihood ratio satisfies $L_{G v}^{*} \equiv \frac{d_{1 v}^{*}}{1-d_{0 v}^{*}}=\frac{2 v_{0}-m}{m \gamma v_{0}}$. Moreover, $L_{G s}^{*}<L_{G v}^{*}$.

Proposition 6 is consistent with our main result that the current shareholders always prefer a less informative information system than that of the firm value maximization. Notice that our main model can be regarded as a special case of Proposition 6 in which the precisions are restricted to be symmetric, $d_{0}=d_{1}$. Proposition 6 also shows that the precisions of signals for the high- and low-value firms have mutual substitutional effects. For any given level of $d_{0}$ or $d_{1}$, we can always adjust the level of the other one such that the current shareholders' payoff or the expected total firm value remains the same.

Moreover, we obtain a similar result regarding the effect of the passage of antitakeover laws on the current shareholders' choice of information system and the firm value maximization. As shown in Proposition 6, the optimal likelihood ratio $L_{G s}^{*}$ decreases with the acquirer's share of the synergy value $(\gamma)$. After the antitakeover laws, the acquirer's bidding is less aggressive due to a smaller share in synergy value. Therefore, the shareholders may respond by endogenously increasing the informativeness of the system to encourage the acquirer's bidding upon a good signal (i.e., $L_{G s}^{* *} \geq L_{G s}^{*}$ ), and the firm value will increase when the shareholders endogenously improve the informativeness.

\subsection{Performance-Based Compensation Contract}

In the main setting, we assume that the private benefit of control $(m)$ is the only payoff that the manager receives. Managers also typically receive performance-based compensations in addition to the private benefit of control. From the corporate governance perspective, manager compensation is an internal governance mechanism. The corporate takeover market is considered an external governance mechanism that is often viewed as a "court of last resort" and is applied when internal governance mechanisms are weak or ineffective (Jensen, 1988). We now extend our model to incorporate a performance-based compensation contract.

For tractability, we consider a binary-effort model to illustrate the effect of the contracts. We assume that the manager's effort is binary, $e \in\left\{e_{l}, e_{h}\right\}$ and $0 \leq e_{l}<e_{h}<1$. Without loss of generality, we assume $e_{l}=0$. Similar to the main setting, the manager's effort determines the probability of high firm value, $\operatorname{Prob}(v=1 \mid e)=e$. The cost of exerting low effort $e_{l}$ is zero, while the cost of exerting high effort $e_{h}$ is $c, c>0$. We also assume that the cost

also have cases in which the optimal likelihood ratios are in a low range to sustain the low-price-bidding equilibrium, but, in general, $L_{G s}^{*} \leq L_{G v}^{*}$ always holds. 
of exerting high effort is not prohibitively high, $\frac{c}{e_{h}}<1$, such that the current shareholders prefer to motivate the manager's high effort rather than low effort.

The manager's effort is unobservable. At time 0, the current shareholders offer a compensation contract to the manager, $w(y) \geq 0$, based on the observed public signal $y$. In a risk-neutral, single-period model with limited liability, it is easy to show that the optimal compensation contract takes the form $w(G)=w$ and $w(B)=0$, where $w$ is the wage offered when a good signal is observed. ${ }^{17}$ The compensation contract is public information, which is a reasonable assumption given that public firms are now required to disclose their incentive compensation packages.

With the compensation contract, the acquirer now conjectures the manager's effort level through the incentives provided by both the compensation contract and the manager's private benefit. Upon a good signal, the acquirer bids either $p_{h}^{g}=1+(1-\gamma) v_{0}-w$ or $p_{l}^{g}=(1-\gamma) v_{0}-w$; upon a bad signal, the acquirer bids either $p_{h}^{b}=1+(1-\gamma) v_{0}$ or $p_{l}^{b}=(1-\gamma) v_{0}$. The offer upon a good signal excludes the compensation to be paid out to the management. Given the offer price, the current shareholders in a low-value firm always tender, and the current shareholders in a high-value firm tender only when a high price $\left(p_{h}^{g}\right.$ or $p_{h}^{b}$ ) is offered.

We follow a similar approach to that in our main setup to obtain the equilibrium efforts and bidding strategies for any given information quality and compensation contracts. We then examine how introducing the compensation contract affects the optimal information quality levels for the current shareholders' payoff and for firm value maximization. The current shareholders can optimally choose both the information quality and compensation contract to maximize their expected payoff. For firm value maximization, the optimal level of information quality is determined when anticipating the compensation contract chosen by shareholders.

In general, the key effects of information quality in our main setting are still present in the setting with the compensation contract. Specifically, higher information quality improves the takeover efficiency by moving the equilibrium to a more aggressive bidding equilibrium; however, the manager's effort is discouraged and, as a result, a higher level of compensation is required to sustain the equilibrium. Compared with the main setting, the information quality plays an additional role in determining the compensation contract efficiency: higher-quality information leads to a more efficient compensation contract in motivating the manager's

\footnotetext{
${ }^{17}$ The reason is that, in equilibrium, both the manager's effort and the acquirer's bidding strategy depend on the difference of two compensation schemes, $w(G)-w(B)$. Therefore, the current shareholders can always reduce $w(B)$ to zero to maximize their expected payoff, yet maintain the manager's effort and the acquirer's bidding strategy in the same equilibrium.
} 
effort. This additional role of information quality leads the optimal information quality to a higher level. Our analysis shows the following findings. ${ }^{18}$

Remark 1 With a compensation contract,

- In general, the optimal information quality that maximizes the expected firm value is perfect $\left(d_{v}^{*}=1\right)$, but the current shareholders prefer a lower-than-perfect level of information quality $\left(d_{s}^{*} \leq 1\right)$.

- In addition, when the manager's private benefit is sufficiently large, we have $d_{s}^{*}<1$, and the optimal compensation contract to maximize the current shareholders' payoff is $w^{*}\left(d_{s}^{*}\right)=0$.

In our main setting, the manager is disciplined only through the external takeover market due to the threat of losing his private benefit, which makes it hard to disentangle the effect of information quality on the takeover efficiency from the effort efficiency. Therefore, a perfect information system is never optimal. In this setting with a compensation contract, however, the contract provides an alternative mechanism to motivate the manager's effort, which is independent from the takeover market. By increasing the information quality, both the effort efficiency and the takeover efficiency can be improved and thus perfect information quality in general is optimal for firm value maximization. When the information quality is perfect, the compensation contract provides the full incentive to motivate the manager to choose high effort.

However, for the current shareholders, they still prefer a lower-than-perfect information quality level. As previously discussed, this is because the current shareholders' objective differs from the firm value maximization: namely, they do not enjoy the full benefit from the takeover market, and they may obtain an overbidding premium. In addition, we find that when the incentive provided by the private benefit of the manager is large enough, the optimal compensation contract to maximize the current shareholders' payoff becomes zero. That is, the current shareholders do not need to use a compensation contract to motivate the manager, and the takeover market becomes the only necessary governance mechanism to discipline the manager in equilibrium. Our main setting can be viewed as the optimal contracting result in this special case.

\footnotetext{
${ }^{18}$ For the results in the Remark, we are able to prove analytically that $d_{v}^{*}=1, d_{s}^{*}<1$, and $w^{*}\left(d_{s}^{*}\right)=0$ when $m$ is sufficiently large. For the case of small $m$, although we are unable to show the mathematical proof due to a complicated multiple equilibria comparison, our numerical results are consistent with the main conclusion. The analytical proof for Remark 1 is available upon request.
} 
Moreover, we obtain a similar result regarding the effect of the passage of antitakeover laws. The optimal information quality for the current shareholders' welfare weakly increases (i.e., $d_{s}^{* *} \geq d_{s}^{*}$ ), and both the current shareholders' welfare and the expected firm value weakly increase.

\section{Conclusions and Empirical Implications}

We develop a theoretical model to examine the interaction between the information quality of financial reporting and the takeover market as a corporate governance mechanism to discipline managers. We find that perfect information quality is not optimal for the maximization of either the current shareholders' expected payoff or the expected firm value. We also highlight the difference between the current shareholders' welfare and the firm value. We show that the current shareholders' choice of information quality level is lower than the socially optimal level because the current shareholders do not enjoy the full synergy value from the takeover. In addition, we examine the effect of antitakeover laws on the optimal information quality choices and the expected firm value. We find that antitakeover laws may increase the total firm value due to the increase of information quality after the passage of antitakeover laws.

Our model provides theoretical explanations for some empirical findings regarding the role of information quality in takeover markets. Our results are consistent with recent empirical findings related to target firms' information quality in takeovers. McNichols and Stubben (2015) and Ramen et al. (2013) show that acquirers are able to bid more effectively and pay less to acquire a target firm that has high-quality accounting information, which is consistent with our theory's predictions. In addition, our model prediction is consistent with the empirical results in Armstrong et al. (2012) that firms increase information quality after the adoption of antitakeover laws.

Our theoretical model also offers some new testable predictions for future empirical research in this area. For example, our analysis indicates that when a target firm's potential share in synergy value is small, the target shareholders would rather keep information quality as low as possible. Moreover, after the passage of antitakeover laws, the firms with larger shares in synergy value are more likely to respond to antitakeover laws and increase the information quality. Hence, although information quality is an endogenous choice in our model, the passage of antitakeover laws provides an exogenous shock to test our model's prediction regarding the impact of the relative share in the synergy value on the information quality choice of the firms. 
In addition, our results suggest that it is important to control the endogenous response of firms when examining the impact of antitakeover laws on firm value. Empirical studies often use the stock market response to antitakeover laws' passage as a measure of a change in the firm value. We predict a cross-sectional variation in stock market reaction among firms that respond differently to the antitakeover laws in their information quality choice.

Our study takes the first step in analytically examining the interaction between financial reporting's information quality and takeover markets. The current model leaves plenty of room for future studies. For example, in the current model we do not consider the conflict of interest between the board and the shareholders, and we assume the board is benevolent and makes decisions to maximize the current shareholders' interest. Future studies can extend our model and consider a case in which the board's interest is not fully aligned with the shareholders. In addition, in the current paper, we do not explicitly model the bargaining over the synergy gains. Future research that can incorporate the endogenous bargaining game between the parties will further enrich our understanding of takeover markets and provide additional insight that our current model does not offer. 


\section{References}

[1] Ahern, K. R., 2012. "Bargaining power and industry dependence in mergers ." Journal of Financial Economics 103, 530-550.

[2] Aktas, N., Bodt, E.d., Roll, R., 2010. "Negotiations under the threat of an auction." Journal of Financial Economics 98, 241-255.

[3] Ambrose, B. W., Megginson, W. L., 1992. "The role of asset structure, ownership structure, and takeover defenses in determining acquisition likelihood." Journal of Financial and Quantitative Analysis 27, 575-589.

[4] Armstrong, C. S., Balakrishnan, K., Cohen, D., 2012. "Corporate governance and the information environment: evidence from state antitakeover laws." Journal of Accounting and Economics 53, 185-204.

[5] Armstrong, C. S., Guay, W. R., Weber, J. P., 2010. "The role of information and financial reporting in corporate governance and debt contracting. " Journal of Accounting and Economics 50, 179-234.

[6] Arya, A., Glover, J., Sivaramakrishnan, K., 1997. "Commitment issues in budgeting." Journal of Accounting Research 35, 273-278.

[7] Arya, A., Glover, J., Sunder, S., 1998. "Earnings management and the revelation principle" Review of Accounting Studies 3, 7-34.

[8] Arya, A., Mittendorf, B., 2011. "The benefits of aggregate performance metrics in the presence of career concerns. " Management Science 57, 1424-1437.

[9] Baldenius, T., Melumad, N., Meng, X., 2014. "Board composition and CEO power." Journal of Financial Economics 112, 53-68.

[10] Bertomeu, J., Beyer, A., Dye, R. A., 2011. "Capital Structure, Cost of Capital, and VoluntaryDisclosures." The Accounting Review 86, 857-886.

[11] Bertrand, M., Mullainathan, S., 2003. "Enjoying the quiet life? Corporate governance and managerial preferences." Journal of Political Economy 111, 1043-1075.

[12] Betton, S., Eckbo, B. E., Thorburn, K. S., 2008. "Corporate takeovers." Handbook of Corporate Finance: Empirical Corporate Finance 2, Chapter 15, 291-430, Elsevier/North-Holland Handbook of Finance Series.

[13] Bhagat, S., Jefferis, R. H., 1993. "Is defensive activity effective?" Working Paper, University of Colorado, Boulder. 
[14] Bradley M., Desai A., Kim E. H., 1988. "Synergistic gains from corporate acquisitions and their division between the stockholders of target and acquiring firms." Journal of Financial Economics 21, 3-40

[15] Bushman, R. M., Smith, A. J., 2001. "Financial accounting information and corporate governance." Journal of Accounting and Economics 32, 237-333.

[16] Caskey, J., Nagar, V., Petacchi, P., 2010. "Reporting bias with an audit committee." The Accounting Review 85, 447-481.

[17] Chen, Q., Hemmer, T., Zhang, Y., 2007, "On the relation between conservatism in accounting standards and incentives for earnings management." Journal of Accounting Research 45, 541-565.

[18] Cheng S., Nagar, V., Rajan, M., 2004. "Identifying control motives in managerial ownership: evidence from antitakeover legislation." Review of Financial Studies 18, 637672.

[19] Comment, R., Schwert, G. W., 1995. "Poison or placebo? Evidence on the deterrence and wealth effects of modern antitakeover measures." Journal of Financial Economics 39, 3-43.

[20] Cremers, M., Ferrell, A., 2014. Thirty years of shareholder rights and firm value. The Journal of Finance 69, 1167-1196.

[21] DeAngelo, H., Rice, E. M., 1983. Antitakeover charter amendments and stockholder wealth. Journal of Financial Economics 11, 329-360.

[22] Devos, E., Kadapakkam, P. R., Krishnamurthy, S., 2009. "How do mergers create value? A comparison of taxes, market power, and efficiency improvements as explanations for synergies." Review of Financial Studies 22, 1179-1211.

[23] Drymiotes, G., 2007. "The monitoring role of insiders." Journal of Accounting and Economics 44, 359-377.

[24] Ekmekci, M., Kos, N., 2016. "Information in tender offers with a large shareholder." Econometrica 84, 87-139.

[25] Fan, Q., Zhang, X., 2012. "Accounting conservatism, aggregation, and information quality. " Contemporary Accounting Review 29, 38-56.

[26] Fee, C. E., Thomas, S., 2004. "Sources of gains in horizontal mergers: evidence from customer, supplier, and rival firms." Journal of Financial Economics 74, 423-460. 
[27] Francis, J. R., Martin, X., 2010. "Acquisition profitability and timely loss recognition." Journal of Accounting and Economics 49, 161-178.

[28] Gigler, F., Hemmer, T., 2001. "Conservatism, optimal disclosure policy, and the timeliness of financial reports." The Accounting Review 76, 471-494.

[29] Hayn, C. 1989. "Tax attributes as determinants of shareholder gains in corporate acquisitions." Journal of Financial Economics 23, 121-53.

[30] Heron, R.A., Lie, E., 2015. The effect of poison pill adoptions and court rulings on firm entrenchment. Journal of Corporate Finance 35, 286-296.

[31] Jensen, M. C., 1988. "The takeover controversy: analysis and evidence." Midland Corporate Finance Journal 4, 6-32.

[32] Kanodia, C., Lee. D., 1998. "Investment and disclosure: the disciplinary role of periodic performance reports." Journal of Accounting Research 36, 33-35.

[33] Kanodia, C., Singh, R., Spero, A. E., 2005. "Imprecision in accounting measurement: can it be value enhancing?" Journal of Accounting Research 43, 487-519.

[34] Kim E. H., Singal V., 1993. "Mergers and market power: evidence from the airline industry. "American Economic Review 83, 549-569.

[35] Kini, O., Kracaw, W., Mian, S., 2004. "The nature of discipline by corporate takeovers." Journal of Finance 59, 1511-1552.

[36] Lambert R. A., Larcker, D. F., 1985. "Golden parachutes, executive decision-making and shareholder wealth." Journal of Accounting and Economics 7, 179-203.

[37] Lambert, R.A., Leuz, C., Verrecchia, R.E., 2007. "Accounting information, disclosure, and the cost of capital." Journal of Accounting Research 45, 385-420.

[38] Langberg, N., P. Kumar, K. Sivaramakrishnan, 2012. "Voluntary disclosures, corporate control, and investment." Journal of Accounting Research 50, 1041-1076.

[39] Laux, V., 2008. "Board independence and CEO turnover." Journal of Accounting Research 46, 137-171.

[40] Laux, C., Laux, V., 2009. "Board committees, CEO compensation, and earnings management." The Accounting Review 84, 869-891.

[41] Martin, K. J., McConnell, J. J., 1991. "Corporate performance, corporate takeovers, and management turnover." Journal of Finance 46, 671-687. 
[42] McNichols, M. F., Stubben, S. R., 2015. "The effect of target-firm accounting quality on valuation in acquisitions." Review of Accounting Studies 20,110-140 .

[43] Moeller, S. B., Schlingemann, F. P., Stulz, R. M., 2005. "Wealth destruction on a massive scale? A study of acquiring-firm returns in the recent merger wave." Journal of Finance 60, 757-782.

[44] Ramen, K., Shivakumar, L., Tamayo, A., 2013. “Targets' earnings quality and bidders' takeover decisions." Review of Accounting Studies 18, 1050-1087.

[45] Romano, R., 1992. "A guide to takeovers: Theory, evidence, and regulations." Yale Journal on Regulation 9, 119-180.

[46] Straska, M., Waller, G., 2014. "Antitakeover provisions and shareholder wealth: A survey of the literature." Journal of Financial and Quantitative Analysis 49, 933956. 


\section{Appendix: Proofs}

\section{Proof. Lemma 1}

We can rewrite Eq. (2) to be

$$
\Pi_{r}(p, \hat{h})= \begin{cases}0, & \text { if } p<p_{l} \\ (1-\hat{h})\left(v_{0}-p\right), & \text { if } p_{l} \leq p<p_{h} \\ (1-\hat{h}) v_{0}+\hat{h}\left(1+v_{0}\right)-p, & \text { if } p \geq p_{h}\end{cases}
$$

From this equation, $\Pi_{r}(p, \hat{h})$ decreases with $p$ when $p \geq p_{h}$ or $p_{l} \leq p<p_{h}$. As a result, the optimal $p$ that maximizes $\Pi_{r}(p, \hat{h})$ will be either $p_{h}$ or $p_{l}$, while all other prices are dominated.

For $p_{l}=(1-\gamma) v_{0}$ and $p_{h}=1+(1-\gamma) v_{0}$, we have $\Pi_{r}\left(p_{l}, \hat{h}\right)=(1-\hat{h}) \gamma v_{0}$ and $\Pi_{r}\left(p_{h}, \hat{h}\right)=$ $\hat{h}+\gamma v_{0}-1$. That is, $\Pi_{r}\left(p_{h}, \hat{h}\right) \leq \Pi_{r}\left(p_{l}, \hat{h}\right)$ if and only if $\hat{h} \leq \frac{1}{1+\gamma v_{0}}$, with the equality holds when $\hat{h}=\frac{1}{1+\gamma v_{0}}$.

Without accounting signals, the acquirer's belief about the probability of a high-value realization is her conjectured effort level, $\hat{h}=\hat{e}$. Therefore, $p^{*}=p_{h}$ when $\hat{e}>\frac{1}{1+\gamma v_{0}}, p^{*}=p_{l}$ when $\hat{e}<\frac{1}{1+\gamma v_{0}}$, and the acquirer is indifferent between $p_{h}$ and $p_{l}$ when $\hat{e}=\frac{1}{1+\gamma v_{0}}$.

\section{Proof. Lemma 2}

Upon observing the accounting signal, the acquirer's belief becomes $h(G)$ and $h(B)$ as in Eq. (3). It is easy to see that $\hat{h}(G) \geq \hat{h}(B)$. From the proof of Lemma 1 , we have $p^{*}=p_{h}$ when $\hat{h}(y)>\frac{1}{1+\gamma v_{0}}, p^{*}=p_{l}$ when $\hat{h}(y)<\frac{1}{1+\gamma v_{0}}$, and the acquirer is indifferent between $p_{h}$ and $p_{l}$ when $\hat{h}(y)=\frac{1}{1+\gamma v_{0}}$.

Given the equations in (3), we have the following results:

- When $\hat{e}>\frac{1}{1+\gamma v_{0}}$ :

- If $\frac{1}{2} \leq d<\frac{\hat{e} \gamma v_{0}}{1-\hat{e}\left(1-\gamma v_{0}\right)}$, we have $\hat{h}(G)>\hat{h}(B)>\frac{1}{1+\gamma v_{0}}$. As a result, $\alpha_{G}=\alpha_{B}=1$.

- If $\frac{\hat{e} \gamma v_{0}}{1-\hat{e}\left(1-\gamma v_{0}\right)} \leq d \leq 1$, we have $\hat{h}(G)>\frac{1}{1+\gamma v_{0}}$ and $\hat{h}(B) \leq \frac{1}{1+\gamma v_{0}}$ (the equality holds when $\left.d=\frac{\hat{e} \gamma v_{0}}{1-\hat{e}\left(1-\gamma v_{0}\right)}\right)$. Therefore, $\alpha_{G}=1 ; \alpha_{B}=0$ if $\frac{\hat{e} \gamma v_{0}}{1-\hat{e}\left(1-\gamma v_{0}\right)}<d \leq 1$ or $\alpha_{B}$ can be any value in $(0,1)$ if $d=\frac{\hat{e} \gamma v_{0}}{1-\hat{e}\left(1-\gamma v_{0}\right)}$.

- When $\hat{e}<\frac{1}{1+\gamma v_{0}}$ :

- If $\frac{1}{2} \leq d<\frac{1-\hat{e}}{1-\hat{e}\left(1-\gamma v_{0}\right)}$, we have $\hat{h}(B)<\hat{h}(G)<\frac{1}{1+\gamma v_{0}}$. As a result, $\alpha_{G}=\alpha_{B}=0$.

- If $\frac{1-\hat{e}}{1-\hat{e}\left(1-\gamma v_{0}\right)} \leq d \leq 1$, we have $\hat{h}(B)<\frac{1}{1+\gamma v_{0}}$ and $\hat{h}(G) \geq \frac{1}{1+\gamma v_{0}}$ (the equality holds when $\left.d=\frac{1-\hat{e}}{1-\hat{e}\left(1-\gamma v_{0}\right)}\right)$. Therefore, $\alpha_{B}=0 ; \alpha_{G}=1$ if $\frac{1-\hat{e}}{1-\hat{e}\left(1-\gamma v_{0}\right)}<d \leq 1$ or $\alpha_{G}$ can be any value in $(0,1)$ if $d=\frac{1-\hat{e}}{1-\hat{e}\left(1-\gamma v_{0}\right)}$. 
- When $\hat{e}=\frac{1}{1+\gamma v_{0}}$ :

- If $d=\frac{1}{2}$, we have $\hat{h}(G)=\hat{h}(B)=\frac{1}{1+\gamma v_{0}}$. Therefore $\alpha_{G}$ and $\alpha_{B}$ can be any value in $(0,1)$.

- If $\frac{1}{2}<d \leq 1$, we have $\hat{h}(G)>\frac{1}{1+\gamma v_{0}}>\hat{h}(B)$. Therefore, $\alpha_{G}=1$ and $\alpha_{B}=0$.

Therefore, we have the following results:

- When the information quality $d$ is sufficiently low, the acquirer sticks to her default bidding strategy.

- When the information quality $d$ is sufficiently high, the acquirer revises her bidding strategy in the following way:

- If $\hat{e}>\frac{1}{1+\gamma v_{0}}$, then $\alpha_{G}=1$, and $\alpha_{B}=0$ or $0<\alpha_{B}<1$.

- If $\hat{e}<\frac{1}{1+\gamma v_{0}}$, then $\alpha_{G}=1$ or $0<\alpha_{G}<1$, and $\alpha_{B}=0$.

- If $\hat{e}=\frac{1}{1+\gamma v_{0}}$, then $\alpha_{G}=1$ and $\alpha_{B}=0$.

\section{Proof. Sustainable Equilibria in Section 3.3}

Given the acquirer's bidding strategy $\left(\alpha_{G}, \alpha_{B}\right)$, the manager's optimal effort that maximizes his expected payoff is derived in Eq. (6):

$$
e^{*}\left(\alpha_{G}, \alpha_{B}\right)=m-m \cdot\left[\alpha_{G} d+\alpha_{B}(1-d)\right] .
$$

In the following, we solve for the equilibrium given the information quality $d$ and the manager's private benefit $m$. We need to check that for the bidding strategies as shown in Lemma 2, the manager's optimal effort in response to the bidding strategies is consistent with the conjectures.

(1). When the acquirer's belief satisfies $\hat{e}>\frac{1}{1+\gamma v_{0}}$ :

(i) If $\frac{1}{2} \leq d<\frac{\hat{e} \gamma v_{0}}{1-\hat{e}\left(1-\gamma v_{0}\right)}$, then $\alpha_{G}^{*}=\alpha_{B}^{*}=1$, which implies $e^{*}=0$ and it does not satisfy the conjecture $\hat{e}>\frac{1}{1+\gamma v_{0}}$.

(ii) If $\frac{\hat{e} \gamma v_{0}}{1-\hat{e}\left(1-\gamma v_{0}\right)}<d \leq 1$, then $\alpha_{G}^{*}=1, \alpha_{B}^{*}=0$, which implies $e^{*}=m(1-d)$. For any $\frac{1}{2}<d<1$ and $0<m<1$, we have $m(1-d)<\frac{1}{2}$. In addition, for $0<v_{0}<1$ and $0<\gamma<1$, we have $\frac{1}{1+\gamma v_{0}}>\frac{1}{2}$. Therefore $m(1-d)<\frac{1}{1+\gamma v_{0}}$, contradicting with the conjecture. Hence this equilibrium does not hold.

(iii) If $d=\frac{\hat{e} \gamma v_{0}}{1-\hat{e}\left(1-\gamma v_{0}\right)}, \alpha_{G}^{*}=1$ and $\alpha_{B}^{*} \in(0,1)$. Thus, $e^{*}=m(1-d)\left(1-\alpha_{B}^{*}\right)$. Similar to case (ii), it can be proved that $m(1-d)\left(1-\alpha_{B}^{*}\right)<\frac{1}{2}<\frac{1}{1+\gamma v_{0}}$. As a result, this equilibrium does not hold. 
(2). When the acquirer's belief satisfies $0 \leq \hat{e}<\frac{1}{1+\gamma v_{0}}$ :

(i) If $\frac{1}{2} \leq d<\frac{1-\hat{e}}{1-\hat{e}\left(1-\gamma v_{0}\right)}$, then $\alpha_{G}^{*}=\alpha_{B}^{*}=0$. Thus, $e^{*}=m$. This equilibrium sustains when $m<\frac{1}{1+\gamma v_{0}}$ and $\frac{1}{2} \leq d<\frac{1-m}{1-m\left(1-\gamma v_{0}\right)}$.

(ii) If $\frac{1-\hat{e}}{1-\hat{e}\left(1-\gamma v_{0}\right)}<d \leq 1$, then $\alpha_{G}^{*}=1, \alpha_{B}^{*}=0$. Thus, $e^{*}=m(1-d)$. We can prove that $\frac{1-e^{*}}{1-e^{*}\left(1-\gamma v_{0}\right)}=\frac{(1-d)\left(d m\left(1-\gamma v_{0}\right)+1-m\right)}{1-(1-d) m\left(1-\gamma v_{0}\right)}+d>d$, contradicting with the condition. The equilibrium does not hold.

(iii) If $d=\frac{1-\hat{e}}{1-\hat{e}\left(1-\gamma v_{0}\right)}$, then $0 \leq \alpha_{G}^{*} \leq 1$ and $\alpha_{B}^{*}=0$. Therefore, $e^{*}=m\left(1-d \alpha_{G}^{*}\right)$.

In equilibrium, $\hat{e}=e^{*}$. Given that $d=\frac{1-\hat{e}}{1-\hat{e}\left(1-\gamma v_{0}\right)}$, we then solve for $\alpha_{G}^{*}$, which gives $\alpha_{G}^{*}=\frac{1}{d} \frac{\gamma v_{0} d m-(1-d)(1-m)}{(1-d) m+\gamma v_{0} d m}$ and $e^{*}=\frac{1-d}{1-d\left(1-\gamma v_{0}\right)}$.

Given that $\alpha_{G}^{*}$ needs to satisfy $0 \leq \alpha_{G}^{*} \leq 1$, we have:

- When $m>\frac{1}{1+\gamma v_{0}}$ and $\frac{1}{2} \leq d<1$, or $m \leq \frac{1}{1+\gamma v_{0}}$ and $\frac{1-m}{1-m\left(1-\gamma v_{0}\right)}<d<1$, $0<\alpha_{G}^{*}<1$.

- When $m \leq \frac{1}{1+\gamma v_{0}}$ and $d=\frac{1-m}{1-m\left(1-\gamma v_{0}\right)}, \alpha_{G}^{*}=0$.

- When $d=1$, we can derive $\alpha_{B}^{*}=0$ and $\alpha_{G}^{*}=1$. In equilibrium, $e^{*}=0$.

(3). When the acquirer's belief is $\hat{e}=\frac{1}{1+\gamma v_{0}}$ :

(i) If $\frac{1}{2}<d \leq 1$, the acquirer's optimal bidding strategy is $\alpha_{G}^{*}=1, \alpha_{B}^{*}=0$. The manager's best response is $e^{*}=m(1-d)$. However, it can be proved that $m(1-d)<$ $\frac{1}{2}<\frac{1}{1+\gamma v_{0}}$. As a result, the equilibrium does not hold.

(ii) If $d=\frac{1}{2}, \alpha_{G}^{*}$ and $\alpha_{B}^{*}$ can be any value in $[0,1]$. Moreover, $\alpha_{G}^{*}$ and $\alpha_{B}^{*}$ are essentially the same, as the signal is completely uninformative. The manager's optimal response is $e^{*}=m\left(1-\frac{\alpha_{G}^{*}+\alpha_{B}^{*}}{2}\right)$.

The equilibrium exists when $m \geq \frac{1}{1+\gamma v_{0}}$ and $\alpha_{G}^{*}+\alpha_{B}^{*}=2\left(1-\frac{1}{m\left(1+\gamma v_{0}\right)}\right) . \quad \alpha_{G}^{*}$ and $\alpha_{B}^{*}$ cannot be uniquely identified. However, in order to be consistent with the other equilibrium, and to make the bidding strategy continuous, we assume that, in this case $\alpha_{B}^{*}=0$ and $\alpha_{G}^{*}=2\left(1-\frac{1}{m\left(1+\gamma v_{0}\right)}\right)$ (which can also be written as $\alpha_{G}^{*}=\frac{1}{d} \frac{\gamma v_{0} d m-(1-d)(1-m)}{(1-d) m+\gamma v_{0} d m}$ with $\left.d=\frac{1}{2}\right){ }^{19}$

To summarize all sustainable equilibria previously discussed, we have three equilibria.

\footnotetext{
${ }^{19}$ If we let $\alpha_{G}^{*}$ and $\alpha_{B}^{*}$ be any value as long as they satisfy $\alpha_{G}^{*}+\alpha_{B}^{*}=2\left(1-\frac{1}{m\left(1+\gamma v_{0}\right)}\right)$, we can still show that the optimal payoff functions for shareholders and firm value remain the same as our current results. All analyses will not be affected.
} 
- When $d=1$, the manager chooses $e^{*}=0$ and the acquirer chooses $\alpha_{G}^{*}=1, \alpha_{B}^{*}=0$ in the equilibrium.

- When $m \leq \frac{1}{1+\gamma v_{0}}$ and $\frac{1}{2} \leq d \leq \frac{1-m}{1-m\left(1-\gamma v_{0}\right)}$ (for our convenience in later proofs, we define this condition as $\mathrm{C} 1$ ), the manager chooses $e^{*}=m$ and the acquirer chooses $\alpha_{G}^{*}=\alpha_{B}^{*}=0$ in the equilibrium.

- When $m \leq \frac{1}{1+\gamma v_{0}}$ and $\frac{1-m}{1-m\left(1-\gamma v_{0}\right)}<d<1$, or $m>\frac{1}{1+\gamma v_{0}}$ and $\frac{1}{2} \leq d<1$ (for our convenience, we define this condition as C2), the manager chooses $e^{*}=\frac{1-d}{1-d\left(1-\gamma v_{0}\right)}$ and the acquirer chooses $\alpha_{G}^{*}=\frac{1}{d} \frac{\gamma v_{0} d m-(1-d)(1-m)}{(1-d) m+\gamma v_{0} d m}$ and $\alpha_{B}^{*}=0$ in the equilibrium.

Notice that $\mathrm{C} 1, \mathrm{C} 2$, and $d=1$ are mutually exclusive conditions about $m$ and $d$. A unique sustainable equilibrium exists under each condition.

\section{Proof. Proposition 1}

The manager's optimal effort is $e^{*}\left(\alpha_{G}, \alpha_{B}\right)=m-m \cdot\left[\alpha_{G} d+\alpha_{B}(1-d)\right]$.

Given the sustainable equilibrium derived above, we can obtain that in equilibrium,

$$
\begin{aligned}
& e^{*}\left(\alpha_{y}^{*}\right)= \begin{cases}0, & \text { given } d=1 ; \\
m, & \text { given } C 1 ; \\
\frac{1-d}{1-d\left(1-\gamma v_{0}\right)}, & \text { given } C 2 .\end{cases} \\
& \alpha_{G}^{*}= \begin{cases}\frac{1}{d} \frac{\gamma v_{0} d m-(1-d)(1-m)}{(1-d) m+\gamma v_{0} d m}, & \text { given } C 2 \text { or } d=1 ; \\
0, & \text { given } C 1 .\end{cases}
\end{aligned}
$$

Therefore $\frac{\partial e^{*}}{\partial d}=\left\{\begin{array}{ll}-\frac{\gamma v_{0}}{\left(1-d\left(1-\gamma v_{0}\right)\right)^{2}}<0, & \text { given } \mathrm{C} 2 ; \\ 0, & \text { given } \mathrm{C} 1 \text { or } \mathrm{d}=1,\end{array}\right.$ and $\frac{\partial \alpha_{G}^{*}}{\partial d}= \begin{cases}\frac{\left(1-\gamma v_{0}\right)\left[1-m\left(1-\gamma v_{0}\right)\right]\left(d-\frac{1-m}{1-\left(1-\gamma v_{0}\right) m}\right)^{2}+\frac{(1-m) \gamma v_{0}}{1-\left(1-\gamma v_{0}\right) m}}{m\left(d-d^{2}+\gamma v_{0} d^{2}\right)^{2}}>0, & \text { given } \mathrm{C} 2 \text { or } \mathrm{d}=1 ; \\ 0, & \text { given } C 1 .\end{cases}$

\section{Proof. Lemma 3}

1) The expected current firm value $E\left[v \mid e^{*}, \alpha_{G}^{*}, \alpha_{B}^{*}\right]=e^{*}\left(\alpha_{y}^{*}\right)$. Hence $E\left[v \mid e^{*}, \alpha_{G}^{*}, \alpha_{B}^{*}\right]$ weakly decreases in $d$.

2) The probability of takeover success is,

$$
\operatorname{Prob}\left(T \mid e^{*}, \alpha_{G}^{*}, \alpha_{B}^{*}\right)=1-e^{*}+e^{*}\left[\alpha_{G}^{*} d+\alpha_{B}^{*}(1-d)\right]= \begin{cases}1, & \text { given } d=1 ; \\ 1-m, & \text { given } C 1 ; \\ 1-\frac{(1-d)^{2}}{m\left(1-d\left(1-\gamma v_{0}\right)\right)^{2}}, & \text { given } C 2 .\end{cases}
$$


We can prove that $\frac{d \operatorname{Prob}\left(T \mid e^{*}, \alpha_{G}^{*}, \alpha_{B}^{*}\right)}{d d}= \begin{cases}0, & \text { given } d=1 ; \\ 0, & \text { given } C 1 ; \\ \frac{2(1-d) v_{0} \gamma}{m\left(1-d\left(1-\gamma v_{0}\right)\right)^{3}}, & \text { given } C 2 .\end{cases}$

Therefore, $\operatorname{Prob}\left(T \mid e^{*}, \alpha_{G}^{*}, \alpha_{B}^{*}\right)$ weakly increases in $d$.

3) The probability of overbidding is,

$\operatorname{Prob}\left(O T \mid e^{*}, \alpha_{G}^{*}, \alpha_{B}^{*}\right)=\left(1-e^{*}\right)\left[(1-d) \alpha_{G}^{*}+d \alpha_{B}^{*}\right]= \begin{cases}0, & \text { given } d=1 \text { or } C 1 ; \\ \frac{(1-d) v_{0} \gamma\left[d m v_{0} \gamma-(1-m)(1-d)\right]}{m\left(1-d\left(1-\gamma v_{0}\right)\right)^{2}}, & \text { given C2. }\end{cases}$

We can prove that given $C 2, \operatorname{Prob}\left(O T \mid e^{*}, \alpha_{G}^{*}, \alpha_{B}^{*}\right)$ is concave and has a unique maximum point at $d=\frac{2-m}{2-m+m \gamma v_{0}}$.

\section{Proof. Proposition 2}

The expected firm value is $\Pi_{v}=E\left[v \mid e^{*}, \alpha_{G}^{*}, \alpha_{B}^{*}\right]+\operatorname{Prob}\left(T \mid e^{*}, \alpha_{G}^{*}, \alpha_{B}^{*}\right) v_{0}$. Substituting $E\left[v \mid e^{*}, \alpha_{G}^{*}, \alpha_{B}^{*}\right]$ and $\operatorname{Prob}\left(T \mid e^{*}, \alpha_{G}^{*}, \alpha_{B}^{*}\right)$ into $\Pi_{v}$, we have

$$
\Pi_{v}= \begin{cases}m+(1-m) v_{0}, & \text { given } C 1 \\ v_{0}+\frac{1-d}{1-d\left(1-\gamma v_{0}\right)}-\frac{(1-d)^{2} v_{0}}{m\left(1-d\left(1-v_{0} \gamma\right)\right)^{2}}, & \text { given } C 2, \text { or } d=1 .\end{cases}
$$

It is easy to show that $\Pi_{v}$ is continuous in both $d$ and $m$. We consider two cases separately: (i) when $m \leq \frac{1}{1+\gamma v_{0}}$, and (ii) when $m>\frac{1}{1+\gamma v_{0}}$. In each case, the choice of information quality $d$ also affects which equilibrium holds. Therefore, we need to compare the payoffs in each possible equilibrium and determine the optimal information quality for the expected firm value.

(1). When $m \leq \frac{1}{1+\gamma v_{0}}$ :

- If $\frac{1}{2} \leq d \leq \frac{1-m}{1-\left(1-\gamma v_{0}\right) m}, C 1$ holds, and the expected firm value is $m+(1-m) v_{0}$ for any information quality in this range.

- If $\frac{1-m}{1-\left(1-\gamma v_{0}\right) m}<d<1, C 2$ holds. We need to solve a constrained optimization problem for $\Pi_{v}$.

Taking the first-order derivative of $\Pi_{v}$ with respect to $d$, we have $\frac{d \Pi_{v}}{d d}=\frac{v_{0} \gamma\left[(1-d)\left(2 v_{0}-m\right)-d m v_{0} \gamma\right]}{m\left(1-d\left(1-v_{0} \gamma\right)\right)^{3}}$.

The first-order condition gives the unconstrained optimal-information quality level in this equilibrium, denoted as $d_{v} \equiv \frac{2 v_{0}-m}{2 v_{0}-m+m \gamma v_{0}}$. We verify that the second-order condition holds.

Next, we need to check whether the interior solution exists for the optimization problem. Notice that $\frac{d \Pi_{v}}{d d}<0$ at $d=1$. Therefore, $d=1$ is never optimal for firm value maximization. 
- If $\frac{1}{2}<v_{0}<1, d_{v}$ satisfies $\frac{1-m}{1-\left(1-\gamma v_{0}\right) m}<d_{v}<1$. The optimal information quality maximizes $\Pi_{v}, d_{v}^{*}=d_{v} \equiv \frac{2 v_{0}-m}{2 v_{0}-m+m \gamma v_{0}}$.

- If $v_{0} \leq \frac{1}{2}$, combined with $m \leq \frac{1}{1+\gamma v_{0}}$, we can prove that $d_{v} \leq \frac{1-m}{1-\left(1-\gamma v_{0}\right) m}$.

Notice that $\Pi_{v}$ is continuous at $d=\frac{1-m}{1-\left(1-\gamma v_{0}\right) m}$. Therefore, the optimal information quality maximizes $\Pi_{v}, d_{v}^{*} \in\left[\frac{1}{2}, \frac{1-m}{1-\left(1-\gamma v_{0}\right) m}\right]$.

(2). When $m>\frac{1}{1+\gamma v_{0}}$ :

With the assumption $m<v_{0}$, we can prove that $m>\frac{1}{1+\gamma v_{0}}$ holds only when $v_{0}>$ $\frac{\sqrt{4 \gamma+1}-1}{2 \gamma}\left(>\frac{1}{2}\right)$.

For any $\frac{1}{2} \leq d<1, C 2$ holds. We have the same unconstrained maximum point $d_{v}$ that maximizes $\Pi_{v}$. We can prove that $\frac{1}{2}<d_{v}<1$. In addition, $\Pi_{v}$ is continuous at $d=1$ and $\frac{d \Pi_{v}}{d d}<0$ at $d=1$. As a result, $d_{v}^{*}=d_{v} \equiv \frac{2 v_{0}-m}{2 v_{0}-m+m \gamma v_{0}}$.

Combining (1) and (2), we conclude that $\begin{cases}d_{v}^{*}=\frac{2 v_{0}-m}{2 v_{0}-m+m \gamma v_{0}}, & \text { if } v_{0}>\frac{1}{2}, \\ d_{v}^{*} \in\left[\frac{1}{2}, \frac{1-m}{1-\left(1-\gamma v_{0}\right) m}\right], & \text { if } v_{0} \leq \frac{1}{2} .\end{cases}$

\section{Proof. Proposition 3}

The expected payoff for the current shareholders is

$\Pi_{s}=E\left[v \mid e^{*}, \alpha_{G}^{*}, \alpha_{B}^{*}\right]+\operatorname{Prob}\left(T \mid e^{*}, \alpha_{G}^{*}, \alpha_{B}^{*}\right)(1-\gamma) v_{0}+\operatorname{Prob}\left(O T \mid e^{*}, \alpha_{G}^{*}, \alpha_{B}^{*}\right)$.

Substituting $E\left[v \mid e^{*}, \alpha_{G}^{*}, \alpha_{B}^{*}\right], \operatorname{Prob}\left(T \mid e^{*}, \alpha_{G}^{*}, \alpha_{B}^{*}\right)$ and $\operatorname{Prob}\left(O T \mid e^{*}, \alpha_{G}^{*}, \alpha_{B}^{*}\right)$ into $\Pi_{s}$, we have

$$
\Pi_{s}= \begin{cases}m+(1-m)(1-\gamma) v_{0}, & \text { given } C 1, \\ \frac{m\left[1-d\left(1-\gamma v_{0}\right)\right]\left[1+v_{0}-d\left(1+v_{0}-v_{0}^{2} \gamma(1-\gamma)\right)\right]-(1-d)^{2} v_{0}}{m\left(1-d\left(1-v_{0} \gamma\right)\right)^{2}}, & \text { given } C 2, \text { or } d=1 .\end{cases}
$$

It's easy to prove that $\Pi_{s}$ is continuous in both $d$ and $m$.

Under the condition $C 2$, we solve the constrained optimization problem for $\Pi_{s}$. Taking the first-order derivative of $\Pi_{s}$ with respect to $d$, we have $\frac{d \Pi_{s}}{d d}=0$ when $d=d_{s} \equiv$ $\frac{2 v_{0}-m\left(1+\gamma v_{0}\right)}{2 v_{0}-m\left(1-\gamma^{2} v_{0}^{2}\right)}$. We verify that the second-order condition holds.

Notice that $\frac{d \Pi_{s}}{d d}<0$ at $d=1$. Therefore, $d=1$ is never optimal for the current shareholders.

Similar to the proof of Proposition 2, we consider all possible cases for the values of $m, v_{0}$, and $\gamma$. In each case, the choice of information quality $d$ also affects which equilibrium holds. We need to compare the payoffs in each possible equilibrium and determine the optimal information quality for the expected firm value. In each case that we consider below, if $C 1$ holds, then $\Pi_{s}=m+(1-m)(1-\gamma) v_{0}$ for any information quality in this range. If $C 2$ 
holds, we then need to check whether the the unconstrained maximum point $d_{s}$ is an interior solution.

Given the assumption $m<v_{0}$, we can prove that $v_{0}>\frac{1}{1+\gamma v_{0}}$ if and only if $v_{0}>$ $\frac{\sqrt{4 \gamma+1}-1}{2 \gamma}\left(>\frac{1}{2}\right)$. Therefore we consider the following cases:

- When $0<v_{0} \leq \frac{\sqrt{4 \gamma+1}-1}{2 \gamma}$, then $m<v_{0}$ implies $m<\frac{1}{1+\gamma v_{0}}$.

- If $0<\gamma \leq 2-\sqrt{2}$ and $\frac{1}{2-\gamma}<v_{0} \leq \frac{\sqrt{4 \gamma+1}-1}{2 \gamma}, d_{s}$ satisfies $\frac{1-m}{1-\left(1-\gamma v_{0}\right) m}<d_{s}<1$. The optimal information quality maximizes $\Pi_{s}$ is $d_{s}^{*}=d_{s} \equiv \frac{2 v_{0}-m\left(1+\gamma v_{0}\right)}{2 v_{0}-m\left(1-\gamma^{2} v_{0}^{2}\right)}$. We then compare $d_{s}^{*}$ with $d_{v}^{*}$. Because $\frac{1}{2-\gamma}>\frac{1}{2}$, the optimal information quality that maximizes firm value is $d_{v}^{*}=d_{v} \equiv \frac{2 v_{0}-m}{2 v_{0}-m+m \gamma v_{0}}$. We can prove that $d_{s}^{*}<d_{v}^{*}$.

- If $0<\gamma \leq 2-\sqrt{2}$ and $0<v_{0} \leq \frac{1}{2-\gamma}$, or $2-\sqrt{2}<\gamma<1$ and $0<v_{0} \leq \frac{\sqrt{4 \gamma+1}-1}{2 \gamma}$, the unconstrained optimal information quality $d_{s} \leq \frac{1-m}{1-\left(1-\gamma v_{0}\right) m}$. Therefore, the optimal information quality maximizes $\Pi_{s}$ is $d_{s}^{*} \in\left[\frac{1}{2}, \frac{1-m}{1-\left(1-\gamma v_{0}\right) m}\right]$. Under this condition, if $v_{0} \leq \frac{1}{2}$, then $d_{s}^{*}, d_{v}^{*} \in\left[\frac{1}{2}, \frac{1-m}{1-\left(1-\gamma v_{0}\right) m}\right]$; if $v_{0}>\frac{1}{2}$, it is then easy to show that $d_{s}^{*} \in\left[\frac{1}{2}, \frac{1-m}{1-\left(1-\gamma v_{0}\right) m}\right]<d_{v}^{*}=d_{v}$.

- When $\frac{\sqrt{4 \gamma+1}-1}{2 \gamma}<v_{0}<1$ and $m<\frac{1}{1+\gamma v_{0}}$, the case is similar to the one above. We need to compare the interior solution $d_{s}$ with $\frac{1-m}{1-\left(1-\gamma v_{0}\right) m}$ for the optimization problem of the shareholder. Because $\frac{\sqrt{4 \gamma+1}-1}{2 \gamma}>\frac{1}{2}$, in this case $d_{v}^{*}=d_{v}$.

- If $0<\gamma \leq 2-\sqrt{2}$ and $\frac{\sqrt{4 \gamma+1}-1}{2 \gamma}<v_{0}<1$, or $2-\sqrt{2}<\gamma<1$ and $\frac{1}{2-\gamma}<v_{0}<1$, $d_{s}$ satisfies $\frac{1-m}{1-\left(1-\gamma v_{0}\right) m}<d_{s}<1$. The optimal information quality maximizes $\Pi_{s}$ is $d_{s}^{*}=d_{s} \equiv \frac{2 v_{0}-m\left(1+\gamma v_{0}\right)}{2 v_{0}-m\left(1-\gamma^{2} v_{0}^{2}\right)}$.

- If $2-\sqrt{2}<\gamma<1$ and $\frac{\sqrt{4 \gamma+1}-1}{2 \gamma}<v_{0}<\frac{1}{2-\gamma}$, we can prove $d_{s} \leq \frac{1-m}{1-\left(1-\gamma v_{0}\right) m}$. Therefore, the optimal information quality maximizes $\Pi_{s}$ is $d_{s}^{*} \in\left[\frac{1}{2}, \frac{1-m}{1-\left(1-\gamma v_{0}\right) m}\right]$.

In both cases, $d_{s}^{*}<d_{v}^{*}$.

- When $\frac{\sqrt{4 \gamma+1}-1}{2 \gamma}<v_{0}<1$ and $v_{0}>m>\frac{1}{1+\gamma v_{0}}, C 2$ holds. In this case $d_{v}^{*}=d_{v}$.

We have the same unconstrained maximum point $d_{s}$ that maximizes $\Pi_{s}$. By checking whether the interior solution exists for the optimization problem, we have:

- If (i) $0<\gamma \leq 2-\sqrt{2}, \frac{\sqrt{4 \gamma+1}-1}{2 \gamma}<v_{0}<\frac{\sqrt{2}-1}{\gamma}$ and $v_{0}>m>\frac{1}{1+\gamma v_{0}}$ or (ii) $0<\gamma \leq 2-\sqrt{2}, \frac{\sqrt{2}-1}{\gamma}<v_{0}<1$ and $\frac{1}{1+\gamma v_{0}}<m<\frac{2 v_{0}}{\left(1+\gamma v_{0}\right)^{2}}$, or (iii) $2-\sqrt{2}<\gamma<1$, $\frac{1}{2-\gamma}<v_{0}<1$ and $\frac{1}{1+\gamma v_{0}}<m<\frac{2 v_{0}}{\left(1+\gamma v_{0}\right)^{2}}, d_{s}$ satisfies $\frac{1}{2}<d_{s}<1$. The optimal information quality maximizes $\Pi_{s}, d_{s}^{*}=d_{s} \equiv \frac{2 v_{0}-m\left(1+\gamma v_{0}\right)}{2 v_{0}-m\left(1-\gamma^{2} v_{0}^{2}\right)}$. 


$$
\begin{aligned}
& - \text { If (i) } 0<\gamma \leq 2-\sqrt{2}, \frac{\sqrt{2}-1}{\gamma}<v_{0}<1 \text { and } \frac{2 v_{0}}{\left(1+\gamma v_{0}\right)^{2}}<m<v_{0} \text { or (ii) } 2-\sqrt{2}<\gamma<1, \\
& \frac{1}{2-\gamma}<v_{0}<1 \text { and } \frac{2 v_{0}}{\left(1+\gamma v_{0}\right)^{2}}<m<v_{0} \text {, or (iii) } 2-\sqrt{2}<\gamma<1, \frac{\sqrt{4 \gamma+1}-1}{2 \gamma}<v_{0}<\frac{1}{2-\gamma}, \\
& \text { and } v_{0}>m>\frac{1}{1+\gamma v_{0}} \text {, then } d_{s}<\frac{1}{2} \text {. The optimal information quality maximizes } \\
& \Pi_{s}, d_{s}^{*}=\frac{1}{2} \text {. }
\end{aligned}
$$

In both cases, $d_{s}^{*}<d_{v}^{*}$.

To summarize the above discussions, we have the following: when $v_{0} \leq \frac{1}{2}, d_{s}^{*}, d_{v}^{*} \in\left[\frac{1}{2}, \frac{1-m}{1-\left(1-\gamma v_{0}\right) m}\right]$; when $v_{0}>\frac{1}{2}, d_{s}^{*}<d_{v}^{*}<1$.

\section{Proof. Proposition 4}

From the proof of Proposition 3 we can obtain the following three scenarios:

- Scenario 1: when (i) $0<\gamma \leq 2-\sqrt{2}, 0<v_{0} \leq \frac{1}{2-\gamma}$, and $m<v_{0}$, or (ii) $2-\sqrt{2}<\gamma<1$, $0<v_{0} \leq \frac{\sqrt{4 \gamma+1}-1}{2 \gamma}$, and $m<v_{0}$, or (iii) $2-\sqrt{2}<\gamma<1, \frac{\sqrt{4 \gamma+1}-1}{2 \gamma}<v_{0} \leq \frac{1}{2-\gamma}$, and $m \leq \frac{1}{1+\gamma v_{0}}$. (i)-(iii) can be rewritten as: $\frac{1}{2}<v_{0}<1,2-\frac{1}{v_{0}}<\gamma<1,0<m<\frac{1}{1+\gamma v_{0}}$, and $0<m<v_{0}$; or $0<v_{0}<\frac{1}{2}$ and $0<m<v_{0}$. In this case, $d_{s}^{*} \in\left[\frac{1}{2}, \frac{1-m}{1-\left(1-\gamma v_{0}\right) m}\right]$. The upper bound of the range of the optimal information quality $\frac{1-m}{1-\left(1-\gamma v_{0}\right) m}$ is decreasing in $\gamma$.

- Scenario 2 (A1): when (i) $0<\gamma \leq 2-\sqrt{2}, \frac{\sqrt{2}-1}{\gamma}<v_{0}<1$ and $\frac{2 v_{0}}{\left(1+\gamma v_{0}\right)^{2}}<m<v_{0}$, or (ii) $2-\sqrt{2}<\gamma<1, \frac{1}{2-\gamma}<v_{0}<1$ and $\frac{2 v_{0}}{\left(1+\gamma v_{0}\right)^{2}}<m<v_{0}$, or (iii) $2-\sqrt{2}<\gamma<1$, $\frac{\sqrt{4 \gamma+1}-1}{2 \gamma}<v_{0}<\frac{1}{2-\gamma}$, and $\frac{1}{1+\gamma v_{0}}<m<v_{0}$. (i)-(iii) can be rewritten as: $\frac{\sqrt{2 v_{0}}-\sqrt{m}}{v_{0} \sqrt{m}}<\gamma<$ $1, \frac{1}{1+\gamma v_{0}}<m<v_{0}$, and $\frac{1}{2}<v_{0}<1$. In this case, $d_{s}^{*}=\frac{1}{2}$.

- Scenario 3 (A2): when (i) $0<\gamma \leq 2-\sqrt{2}, \frac{1}{2-\gamma}<v_{0}<\frac{\sqrt{2}-1}{\gamma}$ and $m<v_{0}$ or (ii) $0<\gamma \leq 2-\sqrt{2}, \frac{\sqrt{2}-1}{\gamma}<v_{0}<1$ and $0<m<\frac{2 v_{0}}{\left(1+\gamma v_{0}\right)^{2}}$, or (iii) $2-\sqrt{2}<\gamma<1$, $\frac{1}{2-\gamma}<v_{0}<1$ and $0<m<\frac{2 v_{0}}{\left(1+\gamma v_{0}\right)^{2}}$. (i)-(iii) can be rewritten as: $0<\gamma<\frac{\sqrt{2 v_{0}}-\sqrt{m}}{v_{0} \sqrt{m}}$ and $\frac{1}{1+\gamma v_{0}}<m<v_{0}$, or $0<\gamma<2-\frac{1}{v_{0}}$ and $0<m<\frac{1}{1+\gamma v_{0}}$, and $\frac{1}{2}<v_{0}<1,0<m<v_{0}$. In this case, $d_{s}^{*}=d_{s} \equiv \frac{2 v_{0}-m\left(1+\gamma v_{0}\right)}{2 v_{0}-m\left(1-\gamma^{2} v_{0}^{2}\right)}$. Furthermore, the interior optimal information quality $d_{s}^{*}$ is decreasing in $\gamma$.

Let $\gamma$ and $\gamma^{\prime}$ be the acquirer's shares of synergy value before and after the adoption of anti-takeover laws, respectively, and $0<\gamma^{\prime}<\gamma<1$. We then consider how the adoption of antitakeover laws affects the conditions for each scenario to hold. If the scenario still holds, it is clear from the above results, that antitakeover laws then increase the optimal information quality. If the scenario does not hold, we need to find a new scenario and compare it with the old scenario. 
- If scenario 1 holds initially, then the optimal information quality after antitakeover laws either remains in the same range, or jumps to scenario 3 when $\gamma$ decreases to $\gamma^{\prime}$. For example, suppose initially $0<\gamma \leq 2-\sqrt{2}, \frac{1}{2}<v_{0} \leq \frac{1}{2-\gamma}$, and $m<v_{0}$ holds. If $\gamma^{\prime}$ is not too small such that $\frac{1}{2}<v_{0} \leq \frac{1}{2-\gamma^{\prime}}$ remains, then scenario 1 still holds with $\gamma^{\prime}$. If $\gamma^{\prime}$ is small enough such that $\frac{1}{2-\gamma^{\prime}}<v_{0}$, then scenario 1 does not hold, but scenario 3 holds. We can show a similar result for all of the conditions under scenario 1 and prove that $d_{s}^{* *} \geq d_{s}^{*}$.

- If scenario 2 holds initially, then either scenario 2 remains, or scenario 1 or scenario 3 holds as $\gamma$ decreases to $\gamma^{\prime}$. For example, suppose initially (i) $0<\gamma \leq 2-\sqrt{2}$, $\frac{\sqrt{2}-1}{\gamma}<v_{0}<1$ and $\frac{2 v_{0}}{\left(1+\gamma v_{0}\right)^{2}}<m<v_{0}$ holds. If $\gamma^{\prime}$ becomes very small such that $v_{0}<\frac{\sqrt{2}-1}{\gamma^{\prime}}$ or $m<\frac{2 v_{0}}{\left(1+\gamma^{\prime} v_{0}\right)^{2}}$, then scenario 3 holds. In the same way, we can show that when (ii) $2-\sqrt{2}<\gamma<1, \frac{1}{2-\gamma}<v_{0}<1$ and $\frac{2 v_{0}}{\left(1+\gamma v_{0}\right)^{2}}<m<v_{0}$, or (iii) $2-\sqrt{2}<\gamma<1$, $\frac{\sqrt{4 \gamma+1}-1}{2 \gamma}<v_{0}<\frac{1}{2-\gamma}$, and $v_{0}>m>\frac{1}{1+\gamma v_{0}}$ initially holds, then after the anti-takeover law, either scenario 2 remains, or scenario 1 or scenario 3 holds. Again, we have $d_{s}^{* *} \geq d_{s}^{*}$.

- If scenario 3 holds initially, then the condition in scenario 3 is relaxed as $\gamma$ decreased to $\gamma^{\prime}$. Therefore, scenario 3 still holds after the anti-takeover law. From the above result, the interior solution is decreasing in $\gamma$, therefore we have $d_{s}^{* *}>d_{s}^{*}$.

\section{Proof. Proposition 5}

We focus on the cases of A1 and A2, where condition C2 holds. In the proofs of Propositions 2 and 3, we have derived the shareholder's expected payoff and the expected firm value given $d$ and $\gamma$ as

$$
\begin{aligned}
& \Pi_{s}(d, \gamma)=\frac{m\left[1-d\left(1-\gamma v_{0}\right)\right]\left[1+v_{0}-d\left(1+v_{0}-v_{0}^{2} \gamma(1-\gamma)\right)\right]-(1-d)^{2} v_{0}}{m\left(1-d\left(1-v_{0} \gamma\right)\right)^{2}}, \\
& \Pi_{v}(d, \gamma)=v_{0}+\frac{1-d}{1-d\left(1-\gamma v_{0}\right)}-\frac{(1-d)^{2} v_{0}}{m\left(1-d\left(1-v_{0} \gamma\right)\right)^{2}} .
\end{aligned}
$$

Recall that the manager's equilibrium effort is $e^{*}(d)=\frac{1-d}{1-d\left(1-\gamma v_{0}\right)}$, and the probability of takeover is $P T^{*}(d)=1-\frac{(1-d)^{2}}{m\left(1-d\left(1-\gamma v_{0}\right)\right)^{2}}$.

We denote $e^{*}$ (and $e^{* *}$ ) and $P T^{*}$ (and $P T^{* *}$ ) to be the manager's equilibrium effort and the probability of takeover before (and after) the passage of antitakeover laws given the optimal information quality levels, $d_{s}^{*}$ and $d_{s}^{* *}$.

For simplicity, we assume after the antitakeover laws, the prevailing scenario does not change. If the scenario changes after the antitakeover laws, for example, if A1 holds with $\gamma$ 
while A2 holds with $\gamma^{\prime}$ after the adoption of antitakeover laws, we can then consider it as a combination of $\mathrm{A} 1$ and $\mathrm{A} 2$, and show that our results remain.

- Under A1, $d_{s}^{*}=d_{s}^{* *}=\frac{1}{2}$. Substitute $d_{s}^{*}$ and $d_{s}^{* *}$ into $\Pi_{s}(d, \gamma)$ and $\Pi_{v}(d, \gamma)$, we obtain that

$$
\begin{aligned}
& \Pi_{s}^{*}(\gamma)=1+v_{0}-\frac{v_{0}}{m\left(1+v_{0} \gamma\right)^{2}}-v_{0} \gamma \\
& \Pi_{v}^{*}(\gamma)=v_{0}-\frac{v_{0}}{m\left(1+v_{0} \gamma\right)^{2}}+\frac{1}{1+\gamma v_{0}}
\end{aligned}
$$

Taking the first-order derivatives, we have $\frac{\partial \Pi_{s}^{*}}{\partial \gamma}=v_{0}\left(\frac{2 v_{0}}{m\left(1+v_{0} \gamma\right)^{3}}-1\right)<0$, and $\frac{\partial \Pi_{v}^{*}}{\partial \gamma}=$ $\frac{v_{0}\left(2 v_{0}-m \gamma v_{0}-m\right)}{m\left(1+v_{0} \gamma\right)^{3}}>0$.

As a result, we have $\Pi_{s}^{*}(\gamma)<\Pi_{s}^{*}\left(\gamma^{\prime}\right)$ and $\Pi_{v}^{*}(\gamma)>\Pi_{v}^{*}\left(\gamma^{\prime}\right)$.

Substituting $d_{s}^{*}$ and $d_{s}^{* *}$ into $e^{*}(d)$ and $P T^{*}(d)$, we obtain $e^{*}=\frac{1}{1+\gamma v_{0}}$, and $e^{* *}=\frac{1}{1+\gamma^{\prime} v_{0}}$; $P T^{*}=1-\frac{1}{m\left(1+\gamma v_{0}\right)^{2}}$ and $P T^{* *}=1-\frac{1}{m\left(1+\gamma^{\prime} v_{0}\right)^{2}}$. It is obvious that $e^{* *}>e^{*}$ and $P T^{* *}<P T^{*}$.

- Under A2, we have $d_{s}^{*}=\frac{2 v_{0}-m-m \gamma v_{0}}{2 v_{0}-m+m \gamma^{2} v_{0}^{2}}, d_{s}^{* *}=\frac{2 v_{0}-m-m \gamma^{\prime} v_{0}}{2 v_{0}-m+m \gamma^{\prime 2} v_{0}^{2}}$. Substituting $d_{s}^{*}$ and $d_{s}^{* *}$ into $\Pi_{s}(d, \gamma)$ and $\Pi_{v}(d, \gamma)$, we obtain that,

$$
\Pi_{s}^{*}(\gamma)=\frac{4 v_{0}^{2}(1-\gamma)+m\left(1+\gamma v_{0}\right)^{2}}{4 v_{0}}
$$

$\Pi_{v}^{*}(\gamma)=\frac{m}{4 v_{0}}+v_{0}-\frac{m v_{0} \gamma^{2}}{4}$.

Taking the first-order derivatives, we have $\frac{\partial \Pi_{s}^{*}}{\partial \gamma}=\frac{1}{2}\left(m-2 v_{0}+m v_{0} \gamma\right)<0$, and $\frac{\partial \Pi_{v}^{*}}{\partial \gamma}=$ $-\frac{1}{2} m v_{0} \gamma<0$. As a result, we have $\Pi_{s}^{*}(\gamma)<\Pi_{s}^{*}\left(\gamma^{\prime}\right)$ and $\Pi_{v}^{*}(\gamma)<\Pi_{v}^{*}\left(\gamma^{\prime}\right)$.

Substituting $d_{s}^{*}$ and $d_{s}^{* *}$ into $e^{*}(d)$ and $P T^{*}(d)$, we obtain $e^{*}=\frac{m\left(1+\gamma v_{0}\right)}{2 v_{0}}$ and $e^{* *}=$ $\frac{m\left(1+\gamma^{\prime} v_{0}\right)}{2 v_{0}} ; P T^{*}=1-\frac{m\left(1+\gamma v_{0}\right)^{2}}{4 v_{0}^{2}}$ and $P T^{* *}=1-\frac{m\left(1+\gamma^{\prime} v_{0}\right)^{2}}{4 v_{0}^{2}}$. It is obvious that $e^{* *}<e^{*}$ and $P T^{* *}>P T^{*}$.

Combining all the cases, we get Proposition 5.

\section{Proof. Proposition 6}

Under the generalized information system, and analogous to the equilibrium in the main setting, denoting $h_{0} \equiv \frac{1}{1+\gamma v_{0}}$, we can derive the equilibrium as follows:

- (separating-price-bidding equilibrium) When $L_{G} \geq \frac{h_{0}(1-m)}{m\left(1-h_{0}\right)}$ and $1 \geq L_{B} \geq$ $\frac{L_{G} h_{0}}{h_{0}(1-m)+m L_{G}\left(2 h_{0}+\left(1-h_{0}\right) L_{G}-1\right)}$, the manager chooses $e^{*}=\frac{m L_{B}\left(L_{G}-1\right)}{L_{G}-L_{B}}$ and the acquirer chooses $\alpha_{G}^{*}=1, \alpha_{B}^{*}=0$.

- (low-price-bidding equilibrium) When $L_{G}<\frac{h_{0}(1-m)}{m\left(1-h_{0}\right)}($ Condition C1'), the manager chooses $e^{*}=m$ and the acquirer chooses $\alpha_{G}^{*}=0, \alpha_{B}^{*}=0$. 
- (mixed-price-bidding equilibrium) When $L_{G} \geq \frac{h_{0}(1-m)}{m\left(1-h_{0}\right)}$ and

$0<L_{B}<\frac{L_{G} h_{0}}{h_{0}(1-m)+m L_{G}\left(2 h_{0}+\left(1-h_{0}\right) L_{G}-1\right)}$ (Condition C2'), the manager's effort is $e^{*}=$ $\frac{h_{0}}{h_{0}+L_{G}\left(1-h_{0}\right)}$. The acquirer chooses $\alpha_{G}^{*}=\frac{\left(L_{G}-L_{B}\right)\left(m h_{0}+m L_{G}\left(1-h_{0}\right)-h_{0}\right)}{m\left(1-L_{B}\right) L_{G}\left(\left(1-h_{0}\right) L_{G}+h_{0}\right)}, \alpha_{B}^{*}=0$.

The shareholder's expected payoff is

$\Pi_{s}\left(L_{G}, L_{B}\right)=e^{*}+\left(1-e^{*}+e^{*} \alpha_{G}^{*} \frac{L_{G}\left(1-L_{B}\right)}{L_{G}-L_{B}}\right)(1-\gamma) v_{0}+\left(1-e^{*}\right) \alpha_{G}^{*} \frac{L_{G}-1}{L_{G}-L_{B}}$.

The expected firm value is $\Pi_{v}\left(L_{G}, L_{B}\right)=e^{*}+\left(1-e^{*}+e^{*} \alpha_{G}^{*} \frac{L_{G}\left(1-L_{B}\right)}{L_{G}-L_{B}}\right) v_{0}$.

When the separating-price-bidding equilibrium sustains, we substitute $\alpha_{G}^{*}=1, \alpha_{B}^{*}=0$ and $e^{*}=\frac{m L_{B}\left(L_{G}-1\right)}{L_{G}-L_{B}}$ into $\Pi_{s}\left(L_{G}, L_{B}\right)$ and solve for the optimal $L_{G}$ and $L_{B}$. We find that the optimal level of likelihood ratios for the current shareholders under the separating-pricebidding equilibrium is a corner solution: $L_{G s}=\frac{2-m}{m \gamma v_{0}}$ and $L_{B s}=\frac{L_{G s} h_{0}}{h_{0}(1-m)+m L_{G s}\left(2 h_{0}+\left(1-h_{0}\right) L_{G s}-1\right)}$. Notice that this optimal corner solution in the separating-price-bidding equilibrium also approaches the conditions for the mixed-price-bidding equilibrium. Therefore, the separatingprice-bidding equilibrium is weakly dominated by the mixed-price-bidding equilibrium. Similarly, we can also prove that the separating-price-bidding equilibrium is a dominated equilibrium for the firm value maximization as well.

When the low-price-bidding equilibrium sustains, $\alpha_{G}^{*}=0, \alpha_{B}^{*}=0$ and $e^{*}=m$. Both the shareholder's expected payoff and the expected firm value are independent of the information system as long as the condition for sustaining the low-price-bidding equilibrium sustains $L_{G}<\frac{h_{0}(1-m)}{m\left(1-h_{0}\right)}$. We do not include this case in the proposition, but even with this case, in general we still have $L_{G s}^{*} \leq L_{G v}^{*}$.

When the mixed-price-bidding equilibrium is the optimal equilibrium, substituting $e^{*}=$ $\frac{h_{0}}{h_{0}+L_{G}\left(1-h_{0}\right)}, \alpha_{G}^{*}=\frac{\left(L_{G}-L_{B}\right)\left(m h_{0}+m L_{G}\left(1-h_{0}\right)-h_{0}\right)}{m\left(1-L_{B}\right) L_{G}\left(\left(1-h_{0}\right) L_{G}+h_{0}\right)}$, and $\alpha_{B}^{*}=0$ into $\Pi_{s}\left(L_{G}, L_{B}\right)$ and $\Pi_{v}\left(L_{G}, L_{B}\right)$, we obtain that $\Pi_{s}\left(L_{G}, L_{B}\right)$ and $\Pi_{v}\left(L_{G}, L_{B}\right)$ are independent of $L_{B}$. Taking the first-order derivative with respect to $L_{G}$, we then obtain the optimal likelihood ratios $L_{G s}^{*}$ and $L_{G v}^{*}$ that satisfy the first-order conditions: $L_{G s}^{*}=\frac{2 v_{0}-m\left(1+\gamma v_{0}\right)}{m \gamma v_{0}\left(1+\gamma v_{0}\right)}$ and $L_{G v}^{*}=\frac{2 v_{0}-m}{m \gamma v_{0}}$. The second-order conditions hold. It is easy to show that $L_{G s}^{*}<L_{G v}^{*}$. 